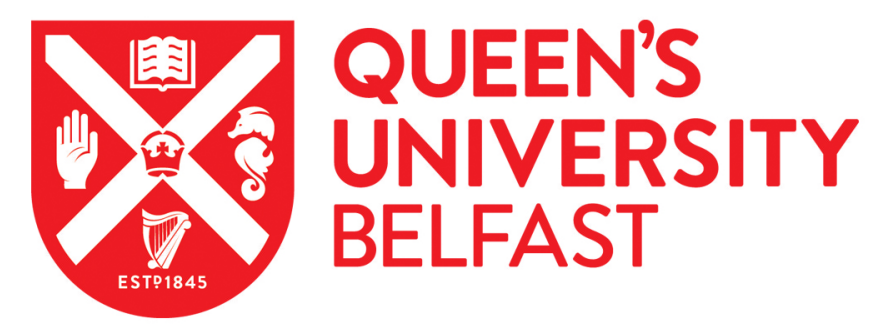

\title{
Psychosocial interventions for stroke survivors, carers and survivor- carer dyads: systematic review and meta-analysis
}

Minshall, C., Pascoe, M. C., Thompson, D. R., Castle, D. J., McCabe, M., Chau, J., Jenkins, Z., Cameron, J. P. C., \& Ski, C. (2019). Psychosocial interventions for stroke survivors, carers and survivor-carer dyads: systematic review and meta-analysis. Topics in stroke rehabilitation, 26(7), 554-564.

https://doi.org/10.1080/10749357.2019.1625173

Published in:

Topics in stroke rehabilitation

Document Version:

Peer reviewed version

Queen's University Belfast - Research Portal:

Link to publication record in Queen's University Belfast Research Portal

Publisher rights

(c) 2019 Informa UK Limited trading as Taylor \& Francis.

This work is made available online in accordance with the publisher's policies. Please refer to any applicable terms of use of the publisher.

\section{General rights}

Copyright for the publications made accessible via the Queen's University Belfast Research Portal is retained by the author(s) and / or other copyright owners and it is a condition of accessing these publications that users recognise and abide by the legal requirements associated with these rights.

Take down policy

The Research Portal is Queen's institutional repository that provides access to Queen's research output. Every effort has been made to ensure that content in the Research Portal does not infringe any person's rights, or applicable UK laws. If you discover content in the Research Portal that you believe breaches copyright or violates any law, please contact openaccess@qub.ac.uk. 


\section{Psychosocial interventions for stroke survivors, carers and survivor-carer dyads: a systematic review and meta-analysis}

Cover title: Stroke psychosocial interventions: a review

*Catherine Minshall, BSW (Catherine.Minshall@myacu.edu.au) $)^{1,2}$

Michaela Pascoe,PhD (Michaela.Pascoe@vu.edu.au) ${ }^{3,4}$

David R. Thompson, PhD (David.Thompson@qub.ac.uk) (5,6 $^{5,6}$

David J. Castle, MD (David.Castle@svha.org.au) 2,5

Marita McCabe, PhD (Marita.McCabe@swinburne.edu.au) ( randomi $^{\text {rabse }}$

Janita P.C. Chau, PhD (Janitachau@cuhk.edu.hk) ${ }^{8}$

Zoe Jenkins, BSc (Zoe.Jenkins@svha.org.au) ${ }^{2}$

Jan Cameron, PhD (Jan.Cameron@monash.edu) ${ }^{9}$

Chantal F. Ski, PhD (C.Ski@qub.ac.uk) $)^{5,6}$

${ }^{1}$ Faculty of Health Sciences, Australian Catholic University, Melbourne, Australia

${ }^{2}$ Mental Health Service, St. Vincent's Hospital, Melbourne, Australia

${ }^{3}$ Institute of Sport, Exercise and Active Living, Victoria University, Melbourne, Australia

${ }^{4}$ Department of Cancer Experiences, Peter MacCallum Cancer Centre, Melbourne, Australia

${ }^{5}$ Department of Psychiatry, University of Melbourne, Melbourne, Australia

${ }^{6}$ School of Nursing and Midwifery, Queen's University, Belfast, United Kingdom

${ }^{7}$ Faculty of Health Sciences, Swinburne University of Technology, Melbourne, Australia

${ }^{8}$ Nethersole School of Nursing, Chinese University of Hong Kong, Shatin, Hong Kong

${ }^{9}$ School of Clinical Sciences, Monash University, Melbourne, Australia

*Corresponding author: St Vincent's Hospital, 41 Victoria Parade, Melbourne, VIC 3065, Australia

Tel: +61 (0)402 064985 e-mail: Catherine.Minshall@myacu.edu.au Twitter@CatMinshall

Key Words: Psychosocial, stroke, survivors, carers, systematic review, meta-analysis

Word count: 2,992

\section{Tables and Figures}

Figure 1: PRISMA flow diagram of included studies

Table 1: Psychosocial components of interventions

Figure 2: Risk of bias

Figure 3: Forest plot - Interventions delivered to stroke survivors or dyads and depressive symptoms measured in stroke survivors

Figure 4: Forest plot - Interventions delivered to carers or dyads and depressive symptoms measured in carers

Figure 5: Forest plot - Interventions delivered to carers or dyads and depressive symptoms measured in stroke survivors

Supplementary Figure. Meta-analysis funnel plots

Supplementary Table. Study characteristics 


\section{Abstract}

Objective: To evaluate the effectiveness of psychosocial interventions on depressive symptoms, anxiety symptoms, quality of life, self-efficacy, coping, carer strain and carer satisfaction among stroke survivors, carers and survivor-carer dyads.

Data sources: MEDLINE, CINAHL, PsycINFO, SocINDEX, Cochrane Library, Web of Science and Scopus databases and the grey literature were searched up to September 2018.

Methods: A systematic review and meta-analysis of randomized controlled trials of psychosocial interventions for stroke survivors, carers and survivor-carer dyads, compared to usual care. Outcomes measured were: depressive symptoms, anxiety symptoms, quality of life, coping, self-efficacy, carer strain and carer satisfaction.

Results: Thirty-one randomized controlled trials $(n=5715)$ were included in the systematic review which found improvements in depressive symptoms, anxiety symptoms, quality of life and coping, though the number of trials assessing each outcome varied. A meta-analysis (11 trials; $n=1280$ ) focusing on depressive symptoms found that in seven trials psychosocial interventions reduced depressive symptoms in stroke survivors (SMD: $-0.36,95 \%$ CI -0.73 to $0.00 ; \mathrm{p}=0.05)$ and in six trials reduced depressive symptoms in carers (SMD: $-0.20,95 \% \mathrm{CI}$ .40 to $0.00 ; \mathrm{p}=0.05)$.

Conclusion: Psychosocial interventions reduced depressive symptoms in stroke survivors and their carers. There was limited evidence that such interventions reduced anxiety symptoms, or improved quality of life and coping for stroke survivors and carers and no evidence that they improved self-efficacy, carer strain or carer satisfaction. 


\section{Introduction}

Stroke can profoundly impair the psychosocial health of stroke survivors and their carers. ${ }^{1-3}$ Psychosocial interventions for stroke survivors, carers and survivor-carer dyads (stroke survivor and carer as single unit) ${ }^{1}$ are yet to be comprehensively reviewed. In reality, psychosocial interventions are rarely defined in stroke literature. As a result, past 'psychosocial' reviews have included behavioural, ${ }^{4}$ psychological $^{3,4}$ or social ${ }^{3}$ interventions. This review defines psychosocial interventions as those comprised of both psychological and social components. ${ }^{5}$ Psychological components address an individuals thought processes and behaviours (e.g., motivational interviewing, counselling), measured using tools that contain psychological sub-scales or questions. ${ }^{6}$ Social components relate to an individual's relationship with others, including spouses, family, friends and the broader community (e.g. family counseling, service links), often measured by sub-scales or questions within validated quality of life scales. ${ }^{7}$ Recent reviews of psychosocial interventions consistent with this definition for coronary heart disease, ${ }^{8}$ chronic kidney disease ${ }^{9}$ and diabetes ${ }^{10}$ have been shown to reduce depression and anxiety. ${ }^{5}$

This is the first review to examine the effectiveness of psychosocial interventions for stroke survivors, carers and survior-carer dyads. Dyadic theory posits that the patient and carer outcomes are inter-related and inter-dependant, ${ }^{11,12}$ therefore, to comprehensively evaluate this literature it is essential to review stroke, carer and dyad using a uniform method. Previously, the fragmented approach to reviewing psychosocial interventions within the stroke population (e.g. survivor, carer, or dyad only reviews $)^{1-4}$ risked omitting key trails from previous reviews and obscuring potential inter-related dydic outcomes. ${ }^{13}$ Limited metaanlysis of this topic makes it difficult to ascertain if psychosocial interventions are effective. $^{14}$ 
The objective of this systematic review and meta-analysis was to evaluate the effectiveness of psychosocial interventions on depressive symptoms, anxiety symptoms, quality of life (QoL), coping, self-efficacy, carer strain and carer satisfaction among stroke survivors, their carers and survivor-carer dyads.

\section{Methods}

The systematic review and meta-analysis of randomized controlled trials (RCTs) was conducted in accordance with Cochrane Collaboration systematic review methodology and Preferred Reporting Items for Systematic Reviews and Meta-Analysis (PRISMA) guidelines. ${ }^{15}$ The review is registered with the PROSPERO database (CRD42017071129).

\section{Criteria}

This review included RCTs of interventions that contained both psychological ${ }^{6}$ and social ${ }^{7}$ components.

Inclusion criteria: clinical diagnosis of ischaemic or haemorrhagic stroke, or carer for a stroke survivor; aged18 years or over; psychosocial intervention (i.e. comprised of at least one psychological and one social component) ${ }^{6,7}$ usual care comparison group; one or more outcomes: depressive symptoms, anxiety symptoms, QoL, coping, self-efficacy, carer strain or carer satisfaction; and RCT. Exclusion criteria: non-English publications, review papers, conference proceedings, dissertations and books.

\section{Search strategy}

Databases searched: MEDLINE, CINAHL, PsycINFO, SocINDEX, Cochrane Library, Web of Science and Scopus databases and grey literature. Search conducted in September 2018 with no year restriction. Relevant unpublished data were requested from authors.

\section{Search terms}


Broad search terms were used to capture as many interventions as possible that could contain psychological and social components. For the same reason, the search strategy forwent the use of the term 'RCT" or its synonyms.

Search terms: (Stroke OR “cerebrovascular accident*” OR

CVA OR “cerebral vascular accident*” OR apoplex*) OR (brain OR cerebr* OR intracran*) N2 (vascular OR ischemi* OR infarct* OR thrombo* OR emboli* OR hemorrhag*) AND (carer* OR caregiver* OR “care giver*” OR caring OR spouse OR famil* OR partner* OR sibling*) AND (Depress* OR melencholi* OR dysthemi* OR mood OR affective disorder OR anxiety OR anxious OR "quality of life" OR coping OR stress OR strain OR satisfaction OR “mental health” OR wellbeing* OR stress* OR strain* OR burden).

\section{Study selection}

Results were uploaded into Covidence online software (http://www.covidence.org) after screening for duplication. Two reviewers screened studies via title, abstract and full text (CM, ZJ) and independently assessed them for inclusion. Authors were contacted if it was unclear if the intervention included psychological or social components; trials in which the authors that did not respond could not be assessed for inclusion. Disagreements were resolved through discussion or consultation with a third reviewer (CFS).

\section{Data extraction}

Means and standard deviations for the meta-analysis of psychosocial interventions were extracted using a customized spreadsheet.

\section{Grades of recommendation, assessment, development and evaluation (GRADE)}

Studies were evaluated as per GRADE recommendations including: risk of bias, heterogeneity, participants, intervention, comparison group, outcome/s, study design (PICOS) 
criteria, precision and publication bias. ${ }^{16}$ Risk of bias was assessed by the two reviewers using Covidence-risk of bias proformas (https://www.covidence.org).

\section{Statistical measures}

For the meta-analysis, the standard mean differences (SMD) of study outcomes were reported as studies used different outcome measures for depressive symptoms and therefore were unable to be converted into a common form. A small effect size was considered to be Hedges' $\mathrm{G}=0.2$, medium was $=0.5$ and large was $=0.8 \cdot{ }^{17}$ Results using completers only were used only when intention-to-treat (ITT) analysis was not reported.

The $p$-value used to determine statistical significance was 0.05 . The $Q$-statistic tests the null hypothesis that all of the studies in the meta-analysis have a common effect size. The $I^{2}$ statistic reports the proportion of observed variance that reflects differences in true effectsizes as opposed to sampling error. $T^{2}$ is the difference between the study variance or variance of true effect sizes. The standard deviation of true-effects is $T$.

\section{Data analysis}

Meta-analysis utilized Comprehensive Meta-Analysis (CMA) software version 3. A randomeffects model was applied. This is because a fixed effect model is only appriate when it can be assumed the true effect size is identical for all studies, ${ }^{18}$ which is not possible for psychological studies that have variations in their delivery and format (e.g., differences in age, socioeconomic factors, length of intervention). ${ }^{19}$ Included studies were weighted by sample size/standard error. We compared the outcomes of the intervention group to usual care.

Publication bias was assessed using a funnel plot. 'One study removed' analyses were used to assess the impact of each study on the combined effect ${ }^{18}$ and the results of this analysis are only reported in text where the removal of a study affected the outcome. 


\section{Results}

\section{Study selection}

The PRISMA flow diagram ${ }^{15}$ is shown in Figure 1.

Figure 1 about here

Figure 1. PRISMA flow diagram of included studies.

\section{Study characteristics}

Thirty-one RCTs were identified; 12 targeted stroke survivors, ${ }^{20-31} 10$ carers, ${ }^{32-41}$ and 11 survivor-carer dyads. ${ }^{31,39,42-50}$ Overall, 3636 stroke survivors and 2079 carers were included between 1997-2018. Sample sizes was 20 to 1008. The mean age of stroke survivors was 57 to 77 years, carers 49 to 76 years. Psychosocial interventions varied in form/content e.g. components, length (Table 1 and Supplementary Table).

Table 1. Psychosocial components of interventions.

\section{Table 1 about here}

\section{GRADE quality assessment}

GRADE assessment was completed for the three meta-analysis. Risk of bias (Figure 2) in the meta-analysisof 'interventions delivered to stroke survivors or dyads and depressive symptoms measured in stroke survivors' found that $61 \%$ of the risk of bias domains were assessed as low. The funnel plots did not indicate publication bias (Supplementary Figure). Heterogeneity was present, likely due to the diverse delivery modes, content and structure of psychosocial interventions. The PICO (i.e. population, interventions, comparison and outcomes) assessed to be satisfactory to address the research question. An assessment of precision considered the sample sizes and the confidence intervals of each trial; four of the 
seven trials had less than 65 participants, therefore the level of evidence was downgraded from high to moderate.

Risk of bias in the meta-analysis of 'interventions delivered to carers or dyads and depressive symptoms measured in carers' found that $55 \%$ of the risk of bias domains were assessed as high or unclear; therefore the level of evidence was downgraded from high to moderate. Funnel plots found no publication bias (Supplementary Figure) and the PICO of the included trials was suitable. An assessment of precision found that one trial ${ }^{47}$ only had 10 participants and a large confidence interval; thus the evidence was downgraded.No unexplained heterogeneity was identified. The level of evidence for this meta-analysis was graded moderate.

Risk of bias in the meta-analysis of 'interventions delivered to carers or dyads and depressive symptoms measured in stroke survivors' found that $54 \%$ of the risk of bias domains were assessed as high or unclear; therefore the level of evidence was downgraded from high to moderate. There was no publication bias (Supplementary Figure), or unexplained heterogeneity and the PICO were assessed as appropriate. Precision was impacted by small participant groups $(n=132)$. Therefore, the level of evidence for this metaanalysis was graded low.

\section{Figure 2 about here}

Figure 2. Risk of bias.

\section{Systematic review results}

\section{Depressive Symptoms}

Depressive symptoms were measured in 25 trials, ${ }^{20-25,27-30,32-34,37,39-47,49,50}$ of which nine interventions reported significant reductions in this outcome: four of the interventions for stroke survivors, ${ }^{22,28-30}$ two for carers ${ }^{33,40}$ and three for survivor-carer dyads. ${ }^{46,47,49}$ Significant 
reductions in depressive symptoms were reported for interventions delivered to stroke survivors that utilized motivational interviewing, ${ }^{29}$ transitional care, ${ }^{30}$ problem solving and psycho education ${ }^{22}$ and anti-depressant medication with behavioural support. ${ }^{28}$ Depressive symptoms increased in one trial for stroke survivors. ${ }^{25}$ Two telephone-based interventions for carers reduced depressive symptoms..$^{33,40}$ One survivor-carer dyad intervention reported a significant reduction in depressive symptoms for stroke survivors but not carers. ${ }^{47}$ Two survivor-carer dyad trials reported a significant reduction in depressive symptoms for carers but not stroke survivors. ${ }^{46,49}$

\section{Anxiety symptoms}

Anxiety symptoms were measured in 10 trials..$^{22,24,25,27,32,37,39,42,44,47}$ One psychoeducation and service links intervention for stroke survivors reported significant reductions in anxiety symptoms. $^{22}$

\section{Quality of life}

Quality of life was measured in 16 trials, ${ }^{20,23-27,30-32,36,37,40,41,45,47,48}$ of which five reported significant improvements in this outcome: three for stroke survivors, ${ }^{24,27,30}$ one for carers ${ }^{36}$ and one for survivor-carer dyads. ${ }^{47}$ Discharge planning, ${ }^{30}$ goal setting ${ }^{24}$ and community rehabilitation ${ }^{27}$ improved QoL in stroke survivors. A telephone and educational peer-support group $^{36}$ for carers improved QoL. A problem solving intervention ${ }^{47}$ improved QoL for survivors in dyads.

\section{Coping}

Coping was measured in six trials, $;^{35,37,38,46,47,50}$ : four of interventions for carers ${ }^{35,37,38,50}$ and two for survivor-carer dyads ${ }^{46,47}$ reported significant improvements. The provision of social support, psycho education and problem solving improved coping in all six trials. ${ }^{47}$ 
Self-efficacy was measured in five trials. ${ }^{23,25,26,37,47}$ three of interventions for stroke survivors,${ }^{23,25,26}$ one for carers ${ }^{37}$ and one for survivor carer-dayds. ${ }^{47}$ Carer strain was measured in two trials ${ }^{34,37}$ and satisfaction measured in three trials. ${ }^{33,42,51}$ No significant improvements were found in these outcomes.

\section{Meta-analysis of depressive symptoms}

Only trials measuring depressive symptoms were subjected to meta-analysis because too few trials provided data, such as means and standard deviations. Thus, 11 trials were included in the meta-analysis of depressive symptoms. ${ }^{20,25,27,28,34,41,44,46,47,49,50}$ Four trials reported multiple time points for outcome measuresments; $;^{25,28,41,49}$ in order to reduce heterogeneity between trials we included the time points most immediately after the conclusion of the intervention in our analyses.

In seven trials $(\mathrm{n}=456)$, the intervention was delivered to stroke survivors or dyads and depressive symptoms were measured in stroke survivors (Figure 3). Four trials used ITT analysis. ${ }^{20,25,27,46}$ The psychosocial intervention showed a small effect, compared to usual care, $\mathrm{Z}=-1.95, \mathrm{p}=0.05, Q$-value $=18.50(6 d f), I^{2}=67.57, T^{2}=0.15, T=0.39$.

Insert Figure 3 about here

Figure 3. Forest plot - Interventions delivered to stroke survivors or dyads and depressive symptoms measured in stroke survivors

In six trials $(\mathrm{n}=561)$, the intervention delivered to carers or dyads and depressive symptoms were measured in carers (Figure 4). Data collection occurred directly after the intervention in four trials, ${ }^{41,47,49,50}$ at 18 weeks only in one trial ${ }^{34}$ and at six months post-intervention in one trial. ${ }^{46}$ In carers, a trend for a small effect of the psychosocial intervention compared to the usual care group was found, $Z=-1.94, p=0.05, Q$-value $=6.30(5 d f), I^{2}=20.62, T^{2}=0.01, T=0.12$. Removal of the latter two trials ${ }^{34,50}$ resulted in a $p$ of 0.04 . 
Figure 4. Forest plot - Interventions delivered to carers or dyads and depressive symptoms measured in carers

In four trials $(n=263)$, the intervention was delivered to carers or dyads and depressive symptoms were measured in stroke survivors that the carers cared for (Figure 5). Two trials used ITT analysis. ${ }^{46,49}$ The psychosocial intervention showed no effect compared to usual care, $\mathrm{Z}=-1.15, p=0.25, Q$-value $=0.31(3 d f), I^{2}=0, T^{2}=0, T=0$.

\section{Insert Figure 5 about here}

Figure 5. Forest plot - Interventions delivered to carers or dyads and depressive symptoms measured in stroke survivors

\section{Discussion}

This systematic review and meta-analysis evaluated the effectiveness of psychosocial interventions compared to usual care on depressive symptoms, anxiety symptoms, QoL, coping, self-efficacy, carer strain and carer satisfaction among stroke survivors, carers and survivor-carer dyads. In stroke survivors, psychosocial interventions reduced depressive symptoms ${ }^{22,28-30}$ and anxiety symptoms ${ }^{22}$ and improved QoL, ${ }^{24,27,30}$ In carers, such interventions reduced depressive symptoms ${ }^{33,40}$ and improved QoL ${ }^{36}$ and coping. ${ }^{35,37,38,50}$ In survivor-carer dyads, they reduced depressive symptoms, ${ }^{46,47,49} \mathrm{QoL},{ }^{47}$ and coping. ${ }^{46,47}$

Community-based interventions for stroke survivors reduced depressive symptoms, ${ }^{28-30}$ considering that around $90 \%$ of stroke survivors return to live in the community this is an important finding. ${ }^{52}$ Although major depression affects around $20 \%$ of hospital-dwelling stroke survivors ${ }^{53}$ only one hospital-based trial ${ }^{22}$ was reduced depressive symptoms. 
Depressive symptoms are often poorly recognized and addressed in clinical practice ${ }^{54}$ despite the call for early intervention. ${ }^{55}$

This review identified a small number psychosocial interventions which reduced depressive symptoms in carers ${ }^{33,40}$ and survivor-carer dyads. ${ }^{46,49}$ One intervention provided the carer with tips to help identify depressive symptoms. ${ }^{40}$ This is important because depressive symptoms often go unrecognised by stroke survivors and carers, as well as clinicians, potentially delaying treatment. ${ }^{56}$ Two interventions, delivered to survivor-carer dyads, reduced depressive symptoms in carers, but not in stroke survivors. ${ }^{46,49}$ This is not surprising as stroke survivors and carers have different support needs. ${ }^{1,2}$ Two interventions ${ }^{46,49}$ delivered to survivor-carer dyads reduced depressive symptoms in carers by targeting carer needs (i.e., tailored support, educational resources). Carers often neglect their own needs, therefore selfcare should be incorporated into future interventions. ${ }^{1,2}$

This is the first meta-analysis to assess the effectiveness of psychosocial interventions on depressive symptoms in stroke survivors, carers and survivor-carer dyads. Our meta-analysis showed that these interventions reduced depressive symptoms, compared to usual care, with a small Hedge's G effect size. Meta-analysis also showed that psychosocial interventions had a small effect on the depressive symptoms of carers, though half of the six trials had less than 40 participants; larger studies will be needed to confirm findings. We found no evidence that psychosocial interventions for carers reduce depressive symptoms in stroke survivors.

Depressive and anxiety symptoms are associated, ${ }^{53}$ but the anxiety remains under-recognised and under-treated amongst stroke survivors. ${ }^{55}$ Only one trial reduced anxiety symptoms in stroke survivors. $^{22}$ This trial recruited stroke survivors within a week of their stroke onset which may have affected the outcomes as clinical status rapidly improves within the first three to six months post-stroke. ${ }^{57,58}$ 
Although, our review found that interventions delivered to survivor-carer dyads decreased depressive symptoms among carers, ${ }^{46,47,49}$ there was no evidence that they reduced anxiety symptoms. Interestingly, none of the included interventions delivered solely to carers included anxiety symptoms as an outcome of interest. This is of concern given that anxiety symptoms are at least as prevalent as depressive symptoms in carers. ${ }^{59,60}$ These findings suggest that interventions need to be more effectively targeted at anxiety as well as depressive symptoms.

Quality of life was reported in five trials: three for stroke survivors stroke three for survivors, ${ }^{24,27,30}$ one for carers ${ }^{36}$ and one for survivor-carer dyads. ${ }^{47}$ This concurs with previous systematic reviews concur that have also found that QoL is difficult to improve. ${ }^{1,3}$ Two of the five trials ${ }^{27,30}$ reported improved stroke survivor QoL ${ }^{27,30}$ through discharge planning and community rehabilitation. Thus these components appear important and should be further investigated as means to promote QoL. Indeed, the absence of effective interventions to improve QoL among stroke survivors may reflect the complexity of the problems that stroke survivors face in enhancing the physical, psychological and social aspects of their health. ${ }^{61}$

Only one trial reported improvements in carer QoL. ${ }^{36}$ In reality, stroke survivors and carers have very different experiences and needs post-stroke. ${ }^{1,3}$ While stroke survivors QoL is often strongly impacted by physical functioning, ${ }^{62}$ that of carers is often affected by the need to adjust to the carer role and a sense of uncertainty. ${ }^{63}$ It is likely that the disparity between the experiences of stroke survivors and carers means that each population requires tailored interventions to address their needs. This may also explain why the intervention delivered to survivor-carer dyads improved the QoL stroke survivors but not carers. ${ }^{47}$

All six trials reporting on coping found improvements; two delivered to survivor-carer dyads ${ }^{46,47}$ and four delivered to carers. Theoretical frameworks were used by all trials 
measuring coping $35,37,38,50,46,47$ utilized such frameworks; this may have contributed to success and therefore should be incorporated into furture interventions.

\section{Limitations}

Currently, psychosocial interventions are not defined, delivered or evaluated according to a consistent definition; this makes the evaluation of these interventions complicated. ${ }^{5}$ There remains some debate about how to define psychosocial interventions. ${ }^{5,8-10}$ None-the-less, we maintain that psychosocial interventions must contain both psychological and social components ${ }^{5}$ and ensured that the included trials reflected this definition.

Nine non-English publications were excluded; this may limitthe evidence-base and geographical representativeness. The quality of the trials in the meta-analysis measuring depressive symptoms in carers was moderate and that of the effectiveness of interventions for survivors and carers measuring depressive symptoms in stroke survivors was low. Likewise, 29 trials in the systematic review were assessed as having an unclear or high risk of bias in one or more domains of assessment.

\section{Conclusions}

Psychosocial interventions reduced depressive symptoms among stroke survivors and, to a lesser extent, their carers. There was limited evidence that such interventions improved anxiety symptoms, QoL and coping for stroke survivors and carers and no evidence that they improved self-efficacy, carer strain and carer satisfaction.

\section{Declaration of conflicting of interests}

The authors declare no potential conflicts of interest with respect to the research, the authorship, and/or publication of this article.

\section{Funding}


Supported by the Australian Government's Collaborative Research Networks (CRN).

\section{Clinical trial registration}

Systematic review registration: CRD42017071129

https://www.crd.york.ac.uk/prospero/display_record.php?RecordID=71129

Online supplemental materials

Supplementary Figure. Meta-analysis funnel plots.

Supplementary Figure. $A, B \& C$ about here

Supplementary Table. Study characteristics 


\section{References}

1. Bakas, T, Clark, P, Kelly-Hayes, M, King, R, Lutz, B, Miller, E. Evidence for stroke family caregiver and dyad interventions: a statement for healthcare professionals from the american heart association and american stroke association. Stroke. 2014;45:28362852. doi: $10.1161 /$ str.0000000000000033

2. Bakas, T, McCarthy, T, Miller, T. An update on the state of the evidence for stroke family caregiver and dyad interventions. Stroke. 2017;48:e122-e125. doi: 10.1161/STROKEAHA.117.016052

3. Cheng, HY, Chair, SY, Chau, JP-C. The effectiveness of psychosocial interventions for stroke family caregivers and stroke survivors: a systematic review and meta-analysis. Patient Educ Couns. 2014;95:30-44. doi: 10.1016/j.pec.2014.01.005

4. Eldred, C, Sykes, C. Psychosocial interventions for carers of survivors of stroke: a systematic review of interventions based on psychological principles and theoretical frameworks. Br J Health Psychol. 2008;13:563-581. No doi.

5. Thompson, DR, Ski, CF. Psychosocial interventions in cardiovascular disease: what are they? Eur J Cardiol. 2013;20:916-917. doi: 10.1177/2047487313494031

6. Gerrig, R, Zimbardo, P. Psychology and life. Boston: Allyn and Bacon. 2002.

7. Northcott, S, Moss, B, Harrison, K, Hilari, K. A systematic review of the impact of stroke on social support and social networks: associated factors and patterns of change. Clin Rehabil. 2015;8:811-831. doi: 0.1177/0269215515602136.

8. Ski, CF, Jelinek, M, Jackson, A, Murphy, B, Thompson, D. Psychosocial interventions for patients with coronary heart disease and depression: a systematic review and meta-analysis. Eur J Cardiovasc Nurs. 2016:15:305-316. doi:

$10.1177 / 1474515115613204$

9. Pascoe, MC, Thompson, DR, Castle, DJ, McEvedy, SM, Ski, CF. Psychosocial interventions for depressive and anxiety symptoms in individuals with chronic kidney disease: systematic review and meta-analysis. Front Psychol. 2017;8:992. doi: 10.3389/fpsyg.2017.00992

10. Pascoe, MC, Thompson, DR, Castle, DJ, Jenkins, ZM, Ski, CF. Psychosocial interventions and wellbeing in individuals with diabetes mellitus: a systematic review and meta-analysis. Front Psychol. 2017;8:2063. doi: 10.3389/fpsyg.2017.02063 
11. Godwin, KM, Swank, PR, Vaeth, P, Ostwald, SK. The longitudinal and dyadic effects of mutuality on perceived stress for stroke survivors and their spousal caregivers. Aging Ment Health. 2013;17:423-431. doi: 10.1080/13607863.2012.756457

12. Lyons, KS, Lee, CS. The theory of dyadic illness management. J Fam Nurs. 2018;24:828. doi: 10.1177/1074840717745669

13. Godwin, KM, Swank, PR, Vaeth, P, Ostwald, SK. The longitudinal and dyadic effects of mutuality on perceived stress for stroke survivors and their spousal caregivers. Aging Ment Health. 2013;17:423-431. doi: 10.1080/13607863.2012.756457

14. Lee, J, Soeken, K, Picot, SJ. A meta-analysis of interventions for informal stroke caregivers. West J Nurs Res. 2007;29:344-356. doi: 10.1177/0193945906296564

15. Moher, D, Liberati, A, Tetzlaff, J, Altman, DG, Goup., TP. Preferred reporting items for systematic reviews and meta- analyses : the prisma statement. Br Med J. 2009;6:e1000097.

16. The Cochrane Collaboration. Cochrane handbook for systematic reviews of interventions: online version (5.1.0, march 2011). 2011; Available from www.cochrane-handbook.org.

17. Durlak, JA. How to select, calculate, and interpret effect sizes. J Pediatr Psychol. 2009;34:917-928. doi: 10.1093/jpepsy/jsp004

18. Borenstein, M, Hedges, L. V., Higgins, J. P. T., Rothstein, H. R. Introduction to metaanalysis. Vol. 1. Chichester: Wiley. 2009.

19. Cleophas, TJ, Zwinderman, AH, Meta-analysis and random effect analysis, in Modern meta-analysis: Review and update of methodologies. Springer International Publishing: Cham.

20. Alexopoulos, GS, Wilkins, VM, Marino, P, Kanellopoulos, D, Reding, M, Sirey, JA et al. Ecosystem focused therapy in poststroke depression: a preliminary study. Int J Geriatr Psychiatry. 2012;27:1053-1060. doi: 10.1002/gps.2822

21. Ertel, KA, Glymour, MM, Glass, TA, Berkman, LF. Frailty modifies effectiveness of psychosocial intervention in recovery from stroke. Clin Rehabil. 2007;21:511-522. doi: $10.1177 / 0269215507078312$ 
22. Fang, $\mathrm{Y}, \mathrm{Mpofu}, \mathrm{E}$, Athanasou, J. Reducing depressive or anxiety symptoms in poststroke patients: pilot trial of a constructive integrative psychosocial intervention. International journal of health sciences. 2017;11:53-58.

23. Glass, T, Berkman, L, Hiltunen, E, Furie, K, Glymour, M, Fay, M et al. The families in recovery from stroke trial: Primary study results. Psychosom Med. 2004;66:889-897. doi: 10.1097/01.psy.0000146326.01642.ca

24. Harrington, R, Taylor, G, Hollinghurst, S, Reed, M, Kay, H, Wood, VA. A communitybased exercise and education scheme for stroke survivors: randomized controlled trial and economic evaluation. Clin Rehabil. 2010;24:3-15. doi:

$10.1177 / 0269215509347437$

25. Hoffmann, T, Ownsworth, T, Eames, S, Shum, D. Evaluation of brief interventions for managing depression and anxiety symptoms during early discharge period after stroke: a pilot randomized controlled trial. Top Stroke Rehabil. 2015;22:116-126. doi: 10.1179/1074935714Z.0000000030

26. Kendall, E, Catalano, T, Kuipers, P, Posner, N, Buys, N, Charker, J. Recovery following stroke: the role of self-management education. Soc Sci Med. 2007;64:735-746. No doi.

27. Markle-Reid, M, Orridge, C, Weir, R, Browne, G, Gafni, A, Lewis, M et al. Interprofessional stroke rehabilitation for stroke survivors using home care. Can J Neurol Sci. 2011;38:317-334. No doi.

28. Mitchell, P, Veith, R, Becker, K, Buzaitis, A, Cain, K, Fruin, M et al. Brief psychosocialbehavioral intervention with antidepressant reduces poststroke depression significantly more than usual care with antidepressant. Living well with stroke: Randomized controlled trial. Stroke. 2009;40:3073-3078. doi: 10.1161/STROKEAHA.109.549808

29. Watkins, CL, Auton, MF, Deans, CF, Dickinson, HA, Jack, CIA, Lightbody, CE et al. Motivational interviewing early after acute stroke - a randomized, controlled trial. Stroke. 2007;38:1004-1009. doi: 10.1161/01.STR.0000258114.28006.d7

30. Wong, FKY, Yeung, SM. Effects of a 4-week transitional care programme for discharged stroke survivors in hong kong: a randomised controlled trial. Health Soc Care Community. 2015;23:619-631. doi: 10.1111/hsc.12177

31. Forster, A, Young, J, Chapman, K, Nixon, J, Patel, A, Holloway, I et al. Cluster randomized controlled trial: clinical and cost-effectiveness of a system of longerterm stroke care. Stroke. 2015;46:2212-2219. doi: 10.1161/STROKEAHA.115.008585 
32. Draper, B, Bowring, G, Thompson, C, Heyst, J, Conroy, P, Thompson, J. Stress in caregivers of aphasic stroke patients: a randomized controlled trial. Clin Rehabil. 2007;21:122-130. doi: 10.1177/0269215506071251

33. Grant, JS, Elliott, TR, Weaver, M, Bartolucci, AA, Giger, JN. Telephone intervention with family caregivers of stroke survivors after rehabilitation. Stroke. 2002;33:20602065. doi: 10.1161/01.str.0000020711.38824.e3

34. Hartke, RJ, King, RB. Telephone group intervention for older stroke caregivers. Top Stroke Rehabil. 2003;9:65-81.

35. Inci, FH, Temel, AB. The effect of the support program on the resilience of female family caregivers of stroke patients: randomized controlled trial. Appl Nurs Res. 2016;32:233 - 240. doi: 10.1016/j.apnr.2016.08.002

36. Larson, J, Franzén-Dahlin, A, Billing, E, Arbin, M, Murray, V, Wredling, R. The impact of a nurse-led support and education programme for spouses of stroke patients: a randomized controlled trial. J Clin Nurs. 2005;14:995-1003. doi: 10.1111/j.13652702.2005.01206.x

37. van den Heuvel, ET, de Witte, LP, Nooyen-Haazen, I, Sanderman, R, Meyboom-de Jong, B. Short-term effects of a group support program and an individual support program for caregivers of stroke patients. Patient Educ Couns. 2000;40:109-120. No doi.

38. van den Heuvel, ET, Witte, LP, Stewart, RE, Schure, LM, Sanderman, R, Meyboom-de Jong, B. Long-term effects of a group support program and an individual support program for informal caregivers of stroke patients: Which caregivers benefit the most? Patient Educ Couns. 2002;47:291-299. No doi.

39. Johnston, M, Bonetti, D, Joice, S, Pollard, B, Morrison, V, Francis, JJ et al. Recovery from disability after stroke as a target for a behavioural intervention: results of a randomized controlled trial. Disabil Rehabil. 2007;29:1117-1127. No doi.

40. Bakas, T, Austin, J, Habermann, B, Jessup, N, McLennon, S, Mitchell, $P$ et al. Telephone assessment and skill-building kit for stroke caregivers: a randomized controlled clinical trial. Stroke. 2015;46:3478-3487. Doi 0.1161/STROKEAHA.115.011099

41. Bakas, T, Farran, C, Austin, J, Given, B, Johnson, E, Williams, L. Stroke caregiver outcomes from the telephone assessment and skill-building kit (TASK). Top Stroke Rehabil. 2009;16:105-121. doi: 10.1310/tsr1602-105 
42. Rodgers, H, Atkinson, C, Bond, S, Suddes, M, Dobson, R, Curless, R. Randomized controlled trial of a comprehensive stroke education program for patients and caregivers. Stroke. 1999;30:2585-2591.

43. Bishop, D, Miller, I, Weiner, D, Guilmette, T, Mukand, J, Feldmann, E et al. Family intervention: Telephone tracking (FITT): a pilot stroke outcome study. Top Stroke Rehabil. 2014;21 Suppl 1:S63-74. doi: 10.1310/tsr21S1-S63

44. Clark, MS, Rubenach, S, Winsor, A. A randomized controlled trial of an education and counselling intervention for families after stroke. Clin Rehabil. 2003;17:703-712. No doi.

45. Goldberg, G, Segal, ME, Berk, SN, Schall, RR, Gershkoff, AM. Stroke transition after inpatient rehabilitation. Top Stroke Rehabil. 1997;4:64-79. No doi.

46. Ostwald, SK, Godwin, KM, Cron, SG, Kelley, CP, Hersch, G, Davis, S. Home-based psychoeducational and mailed information programs for stroke-caregiving dyads post-discharge: a randomized trial. Disabil Rehabil. 2014;36:55-62. Doi: 10.3109/09638288.2013.777806

47. Robinson-Smith, G, Harmer, C, Sheeran, R, Bellino Vallo, E. Couples' coping after stroke: a pilot intervention study. Rehabil Nurs. 2016;41:218-229. doi: 10.1002/rnj.213

48. Shyu, YI, Kuo, LM, Chen, MC, Chen, ST. A clinical trial of an individualised intervention programme for family caregivers of older stroke victims in taiwan. J Clin Nurs. 2010;19:1675-1685. doi: 10.1111/j.1365-2702.2009.03124.x

49. Smith, GC, Egbert, N, Dellman-Jenkins, M, Nanna, K, Palmieri, PA. Reducing depression in stroke survivors and their informal caregivers: a randomized clinical trial of a web-based intervention. Rehabil Psychol. 2012;57:196-206. doi: $10.1037 / a 0029587$

50. Cheng, HY, Chair, SY, Chau, JPC. Effectiveness of a strength-oriented psychoeducation on caregiving competence, problem-solving abilities, psychosocial outcomes and physical health among family caregiver of stroke survivors: a randomised controlled trial. Int J Nurs Stud. 2018;87:84-93. doi: 10.1016/j.ijnurstu.2018.07.005

51. Johnson, W, Onuma, O, Owolabi, M, Sachdev, S. Stroke: a global response is needed. Bull World Health Organ. 2016;94:634. 
52. Australian Institute of Health and Welfare. Stroke and its management in Australia: An update. AlHW: Canberra. 2013.

53. Robinson, RG, Ricardo, J. Post-stroke depression: a review. Am J Psychiatry. 2016;173:221-231. doi:10.1176/appi.ajp.2015.15030363

54. Towfighi, LA, Ovbiagele, EB, El Husseini, MN, Hackett, HM, Jorge, ER, Kissela, AB et al. Poststroke depression: a scientific statement for healthcare professionals from the american heart association/american stroke association. Stroke. 2017;48:e30-e43. doi: 10.1161/STR.0000000000000113

55. Winstein, JC, Stein, RJ, Arena, CR, Bates, JB, Cherney, LL, Cramer, ES et al. Guidelines for adult stroke rehabilitation and recovery: a guideline for healthcare professionals from the American Heart Association/American Stroke Association. Stroke. 2016;47:e98-e169. doi: 10.1161/STR.0000000000000098

56. Klinedinst, JN, Dunbar, BS, Clark, CP. Stroke survivor and informal caregiver perceptions of poststroke depressive symptoms. J Neurosci Nurs. 2012;44:72-81. doi: 10.1097/JNN.0b013e3182477944

57. Dhamoon, SM, Moon, PY, Paik, CM, Sacco, LR, Elkind, SVM. Trajectory of functional decline before and after ischemic stroke: the northern manhattan study. Stroke. 2012;43:2180-2184. doi: 10.1161/STROKEAHA.112.658922

58. Lee, BK, Lim, HS, Kim, HK, Kim, JK, Kim, RY, Chang, NW et al. Six-month functional recovery of stroke patients: a multi-time-point study. Int J Rehabil Res. 2015;38:173180. doi: 10.1097/MRR.0000000000000108

59. Greenwood, N, Mackenzie, A. An exploratory study of anxiety in carers of stroke survivors. J Clin Nurs. 2010;19:2032-2038. doi: 10.1111/j.1365-2702.2009.03163.x

60. Hu, P, Yang, Q, Kong, L, Hu, L, Zeng, L. Relationship between the anxiety/depression and care burden of the major caregiver of stroke patients. Medicine. 2018;97:e12638. doi: 10.1097/MD.0000000000012638

61. Kruithof, WJ, van Mierlo, ML, Visser-Meily, JMA, van Heugten, CM, Post, MWM. Associations between social support and stroke survivors' health-related quality of life-a systematic review. Patient Educ Couns. 2013;93:169-176. doi: 10.1016/j.pec.2013.06.003

62. Aidar, FJ, de Oliveira, RJ, Silva, AJ, de Matos, DG, Carneiro, AL, Garrido, N et al. The influence of the level of physical activity and human development in the quality of 
life in survivors of stroke. Health Qual Life Outcomes. 2011;9:89-89. doi: 10.1186/1477-7525-9-89

63. Lou, S, Carstensen, K, Jørgensen, CR, Nielsen, CP. Stroke patients' and informal carers' experiences with life after stroke: an overview of qualitative systematic reviews. Disabil Rehabil. 2017;39:301-313. doi: 10.3109/09638288.2016.1140836 


\section{Tables}

Table 1. Psychosocial components of interventions

\begin{tabular}{|c|c|c|c|c|c|c|c|}
\hline Author/s & $\begin{array}{l}\text { Personnel } \\
\text { delivering the } \\
\text { intervention }\end{array}$ & $\begin{array}{l}\text { Psychological } \\
\text { component }\end{array}$ & Social component & $\begin{array}{l}\text { Topics } \\
\text { addressed/componen } \\
\text { ts }\end{array}$ & $\begin{array}{l}\text { Individual/ } \\
\text { group/dyad }\end{array}$ & $\begin{array}{l}\text { Delivery } \\
\text { mode }\end{array}$ & $\begin{array}{l}\text { Intervention } \\
\text { duration }\end{array}$ \\
\hline $\begin{array}{l}\text { Alexopoulos et } \\
\text { al., } 2012^{20}\end{array}$ & Therapist & $\begin{array}{l}\text { Problem solving; } \\
\text { cognitive/behavioral } \\
\text { support }\end{array}$ & Family/social support & $\begin{array}{l}\text { Problem solving; } \\
\text { community support }\end{array}$ & Individual & In person & $12 \mathrm{wk}$ \\
\hline $\begin{array}{l}\text { Bakas et al., } \\
2009^{41}\end{array}$ & Nurse & $\begin{array}{l}\text { Problem solving; } \\
\text { stress/behavioral } \\
\text { management }\end{array}$ & $\begin{array}{l}\text { Communication; } \\
\text { service links }\end{array}$ & $\begin{array}{l}\text { Behavioral support; } \\
\text { service links }\end{array}$ & Individual & Telephone & $8 w k$ \\
\hline $\begin{array}{l}\text { Bishop et al., } \\
2014^{43}\end{array}$ & $\begin{array}{l}\text { Family } \\
\text { therapist; }\end{array}$ & Psycho-education & Family resources & $\begin{array}{l}\text { Problem solving; } \\
\text { family functioning }\end{array}$ & Dyad & Telephone & $6 m$ \\
\hline
\end{tabular}




\begin{tabular}{|c|c|c|c|c|c|c|c|}
\hline & nurse & & & & & & \\
\hline Cheng et al. & Nurse & Psycho-education; & Dyad support; social & Problem solving; & Dyad & Telephone, & $26 w$ \\
\hline \multirow[t]{3}{*}{$2018^{50}$} & & coping skills training; & support & coping; social & & in person & \\
\hline & & strengths-based & & support; carer & & & \\
\hline & & & & competence & & & \\
\hline Clark et al., & Social worker & Counseling & Family functioning & Counseling & Dyad & In person & $3.5 \mathrm{~m}$ \\
\hline \multicolumn{8}{|l|}{$2003^{44}$} \\
\hline Draper et al., & Social worker; & Psycho-education & Communication & Service links; stress & Group & In person & $4 w k$ \\
\hline $2007^{32}$ & psychologist & & & management & & & \\
\hline Ertel et al., & Social worker; & Cognitive behavioural & Social support; & Self-efficacy; stress & Individual & In person & $12 w k$ \\
\hline \multirow[t]{2}{*}{$2007^{21}$} & psychologist & therapy & services links & management; & carer/ health & & \\
\hline & & & & problem solving & professional & & \\
\hline Fang et al., & Not stated & Problem solving; & Services links & Psycho-education; & Individual & In person & Not stated \\
\hline \multirow[t]{2}{*}{$2017^{22}$} & & Psycho-education & & stress management; & & & \\
\hline & & & & coping; problem & & & \\
\hline
\end{tabular}




\begin{tabular}{|c|c|c|c|c|c|c|c|}
\hline & & & & solving; service links & & & \\
\hline Forster et al., & Stroke & Problem solving & Healthcare/service & Goal setting; service & Individual & In person & Not stated \\
\hline $2015^{31}$ & coordinators & & links & links & & & \\
\hline Glass et al., & Mental health & Self-efficacy & Family systems & Social/emotional/beh & Individual/ & In person & $6 m$ \\
\hline \multirow[t]{3}{*}{$2004^{23}$} & worker; social & & & avioral support & carer/family & & \\
\hline & worker; & & & & & & \\
\hline & psychologist & & & & & & \\
\hline Goldberg et al., & Psychiatrist; & Stress management & Community resources & Stress management; & Individual/dy & In person & Not stated \\
\hline \multirow[t]{4}{*}{$1997^{45}$} & psychologist; & & & problem solving; & ad & & \\
\hline & recreational & & & community links & & & \\
\hline & therapist; & & & & & & \\
\hline & social worker & & & & & & \\
\hline Grant et al., & Nurse & Social problem solving & Social problem solving & Problem solving; & Dyad & Telephone, & $12 w k$ \\
\hline $2002^{33}$ & & & & family support & & in person & \\
\hline Harrington et & Rehabilitation & Goal setting & Social participation; & Peer support; goals & Group & In person & $8 w k$ \\
\hline
\end{tabular}




\begin{tabular}{|c|c|c|c|c|c|c|c|}
\hline al., $2010^{24}$ & clinicians; & & peer activities & & & & \\
\hline & psychologist & & & & & & \\
\hline Hartke et al., & Psychologist; & Psycho-education & Communication & Dyad/emotional/beha & Group & Telephone & $8 w k$ \\
\hline \multirow[t]{2}{*}{$2003^{34}$} & social worker; & & & viorial support; & & & \\
\hline & nurse & & & community links & & & \\
\hline Hoffmann et & Psychologist; & Cognitive behavioural & Family support & Intervention 1- & Individual & In person & $8 w k$ \\
\hline \multirow[t]{8}{*}{ al., $2015^{25}$} & occupational & therapy; psycho- & & Coping: & & & \\
\hline & therapist & education; & & cognitive/behavioral & & & \\
\hline & & motivational & & support; coping; & & & \\
\hline & & interviewing; coping & & psycho-education & & & \\
\hline & & & & Intervention 2 - Self- & & & \\
\hline & & & & management: & & & \\
\hline & & & & problem solving; & & & \\
\hline & & & & services links & & & \\
\hline Inci et al., & Clinician & Problem solving; & Family support & Family support & Individual/gr & In person & $10 w k$ \\
\hline
\end{tabular}




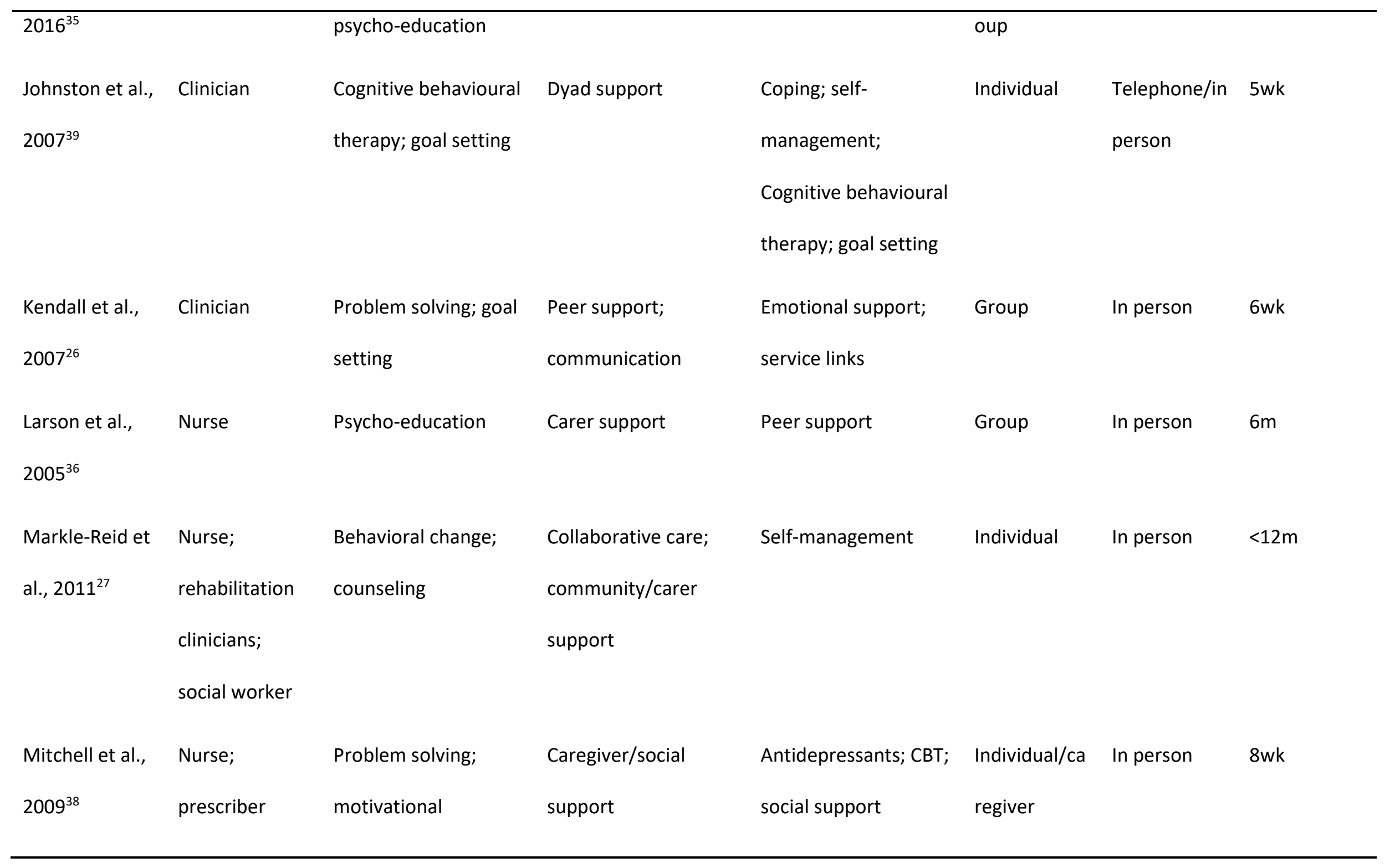




\begin{tabular}{|c|c|c|c|c|c|c|c|}
\hline & & interviewing & & & & & \\
\hline Ostwald et al., & Nurse; & Counseling & Community links & Coping; community & Dyad & Telephone/in & Psychosocial: \\
\hline \multirow[t]{4}{*}{$2014^{46}$} & occupational & & & links; stress & & person & $6 \mathrm{~m}$. \\
\hline & therapist; & & & management & & & Information: \\
\hline & physical & & & & & & $12 \mathrm{~m}$ \\
\hline & therapist & & & & & & \\
\hline Robinson- & Nurse & Problem solving; & Family/dyad & Counseling; goal & Dyad & In person & 6 sessions \\
\hline Smith et al., & & coping skills; self- & functioning & setting; & & & \\
\hline \multirow[t]{2}{*}{$2016^{47}$} & & efficacy; counseling & & communication; & & & \\
\hline & & & & social/dyad support & & & \\
\hline Rodgers et al., & Rehabilitation & Psycho-education; & Communication & Communication & Group/indivi & Telephon/in & 6 sessions \\
\hline \multirow[t]{4}{*}{$1999^{42}$} & clinicians; & behavioral support & & & dual & person & \\
\hline & nurse; & & & & & & \\
\hline & psychologist; & & & & & & \\
\hline & social worker; & & & & & & \\
\hline
\end{tabular}




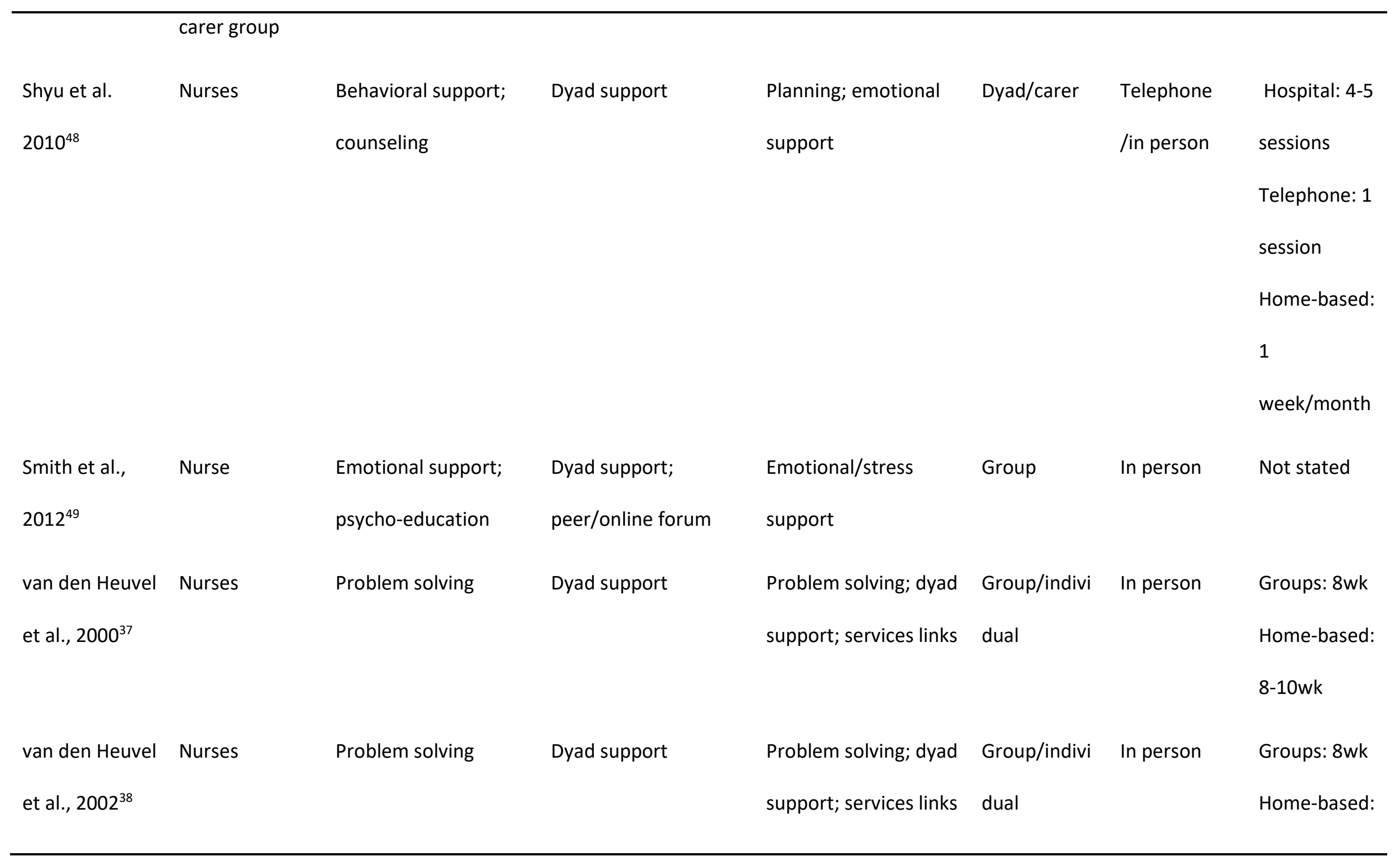




\begin{tabular}{|c|c|c|c|c|c|c|c|}
\hline & & & & & & & 8-10wk \\
\hline Watkins et al., & Nurse; & Motivational & Social support & Counseling; social & Individual & In person & $4 w k$ \\
\hline \multirow[t]{2}{*}{$2007^{29}$} & psychologist & interviewing & & support; goal setting; & & & \\
\hline & & & & self-efficacy & & & \\
\hline Wong et al., & Nurse & Behavior support & Family support & Behavioral/emotional & Individual & In person & $5 w k$ \\
\hline $2015^{30}$ & & & & /family/social support & & & \\
\hline
\end{tabular}


Supplementary Table. Study characteristics

\begin{tabular}{|c|c|c|c|c|c|c|c|}
\hline Reference & Country & Setting & Participants & $\begin{array}{l}\text { Intervention } \\
\text { group }\end{array}$ & Control group & $\begin{array}{l}\text { Time of } \\
\text { assessment }\end{array}$ & $\begin{array}{l}\text { Relevant } \\
\text { outcome } \\
\text { measures }\end{array}$ \\
\hline $\begin{array}{l}\text { Alexopoulos et } \\
\text { al., } 2012^{20}\end{array}$ & USA & $\begin{array}{l}\text { Hospital } \\
\text { rehabilitation } \\
\text { and home-based }\end{array}$ & $\begin{array}{l}\text { SS depressed } \\
\text { (randomized } \\
\mathrm{n}=24 \text { ) }\end{array}$ & $\begin{array}{l}\text { SS Education and } \\
\text { psychosocial } \\
\text { counseling } \\
\text { (n=12; mean age } \\
72 \text {; female=6 } \\
\text { [50\%]) }\end{array}$ & $\begin{array}{l}\text { SS Education } \\
\text { only ( } n=12 ; \\
\text { mean age 69; } \\
\text { female=5 [42\%]) }\end{array}$ & Pre-post & HAM-D, SIS \\
\hline $2009^{41}$ & & & $n=40$ ) & $\begin{array}{l}\text { psychosocial } \\
\text { counseling } \\
\text { (n=12; mean age } \\
72 \text {; female=6 }\end{array}$ & $\begin{array}{l}\text { and active } \\
\text { listening ( } n=19 ; \\
\text { mean age } 58 ; \\
\text { female=16 }\end{array}$ & & 9 \\
\hline
\end{tabular}




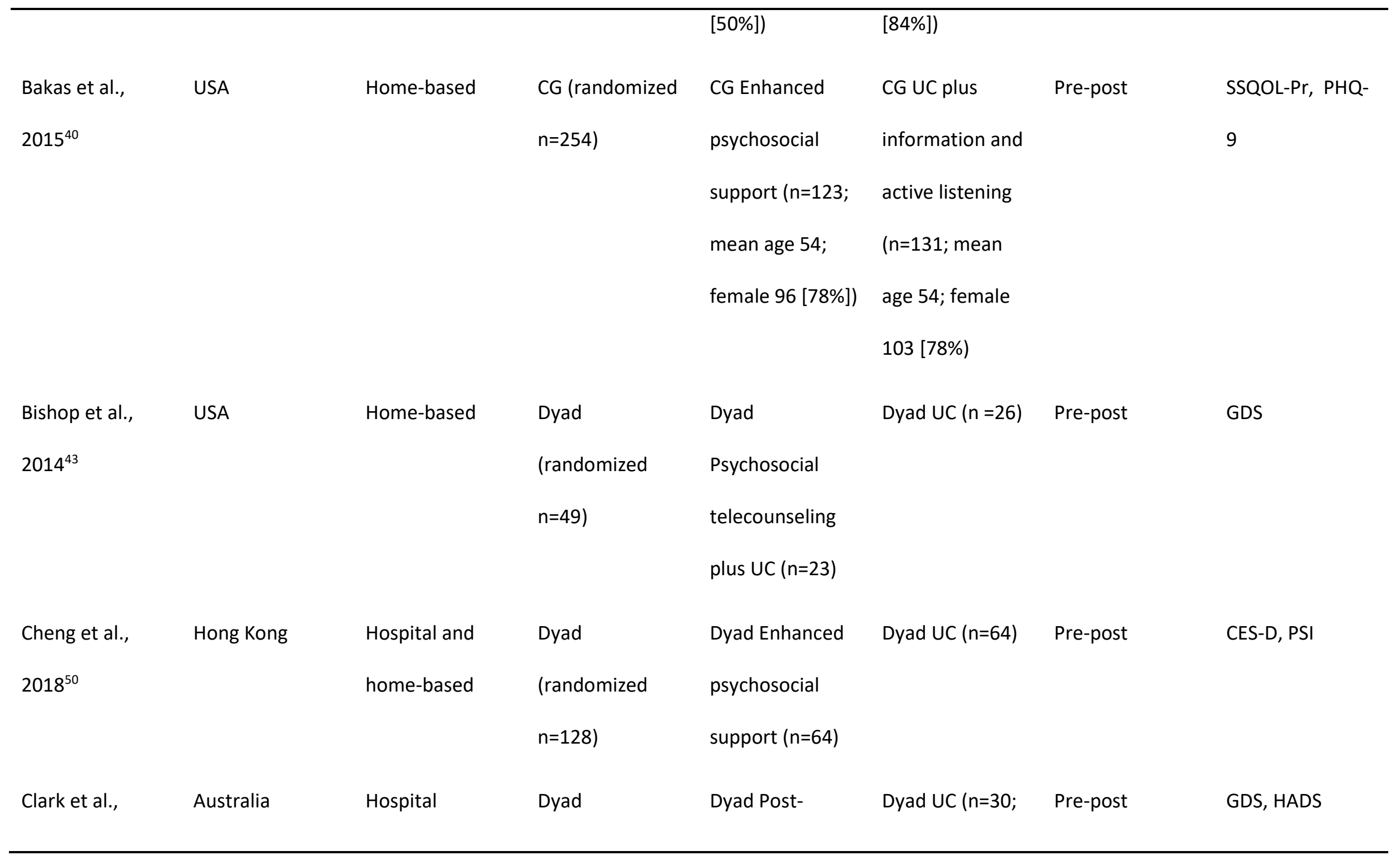




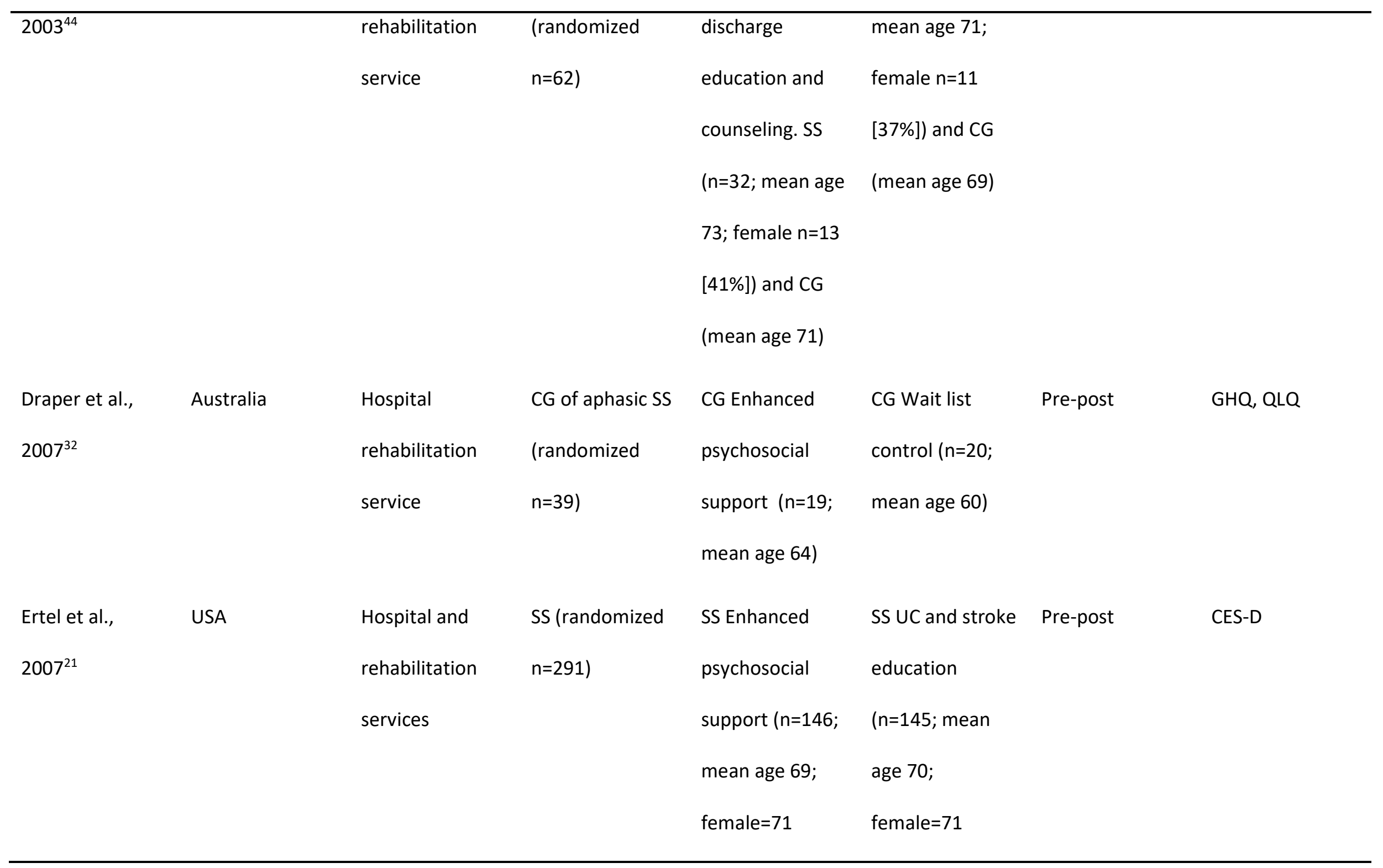




\begin{tabular}{|c|c|c|c|c|c|c|c|}
\hline & & & & [49\%]) & [49\%]) & & \\
\hline Fang et al., & Singapore & Hospital & SS (randomized & SS Enhanced & SS UC (n=19) & Pre-post & HADS \\
\hline \multirow[t]{2}{*}{$2017^{22}$} & & & $n=42)$ & psychosocial & & & \\
\hline & & & & support ( $n=23)$ & & & \\
\hline Forster et al., & UK & Home-based & Dyads and single & Dyad and single & Dyad and single & Pre-post & $E Q-5 D$ \\
\hline \multirow[t]{10}{*}{$2015^{31}$} & & & SS (randomized & SS Longer term & SS UC SS (n=399; & & \\
\hline & & & SS $n=800$ and $C G$ & stroke care. SS & mean age $72 ;$ & & \\
\hline & & & $n=208$ ) & $(\mathrm{n}=401 ;$ mean & female $n=181$ & & \\
\hline & & & & age $71 ;$ & $[45 \%])$ and $C G$ & & \\
\hline & & & & female $=186$ & $(n=100 ;$ mean & & \\
\hline & & & & [46\%]) and CG & age 61 ; female & & \\
\hline & & & & ( $n=108 ;$ mean & $68[68 \%])$ & & \\
\hline & & & & age 61; & & & \\
\hline & & & & female $=73$ & & & \\
\hline & & & & [68\%]) & & & \\
\hline
\end{tabular}




\begin{tabular}{|c|c|c|c|c|c|c|c|}
\hline Glass et al., & USA & Home-based & SS (randomized & SS Enhanced & SS UC and & Pre-post & CES-D, REFFI, \\
\hline $2004^{23}$ & & & $n=291)$ & $\begin{array}{l}\text { psychosocial } \\
\text { support ( } n=143 \text {; } \\
\text { mean age } 69 ; \\
\text { female } n=70 \\
[48 \%])\end{array}$ & $\begin{array}{l}\text { standard stroke } \\
\text { information } \\
\text { (n=141; mean } \\
\text { age } 70 \text {; female } \\
n=70[50 \%] \text { ) }\end{array}$ & & QoL 5-item scale \\
\hline Goldberg et al., & USA & Home-based & Dyad & Dyad Case & Dyad UC ( $n=20 ;$ & Pre-post & CES-D, QoL scale \\
\hline $1997^{45}$ & & & $\begin{array}{l}\text { (randomized } \\
\mathrm{n}=41 \text { ) }\end{array}$ & $\begin{array}{l}\text { management } \\
\text { post-discharge } \\
\text { (n=21; median } \\
\text { age } 72 \text {; female } \\
n=11[52 \%])\end{array}$ & $\begin{array}{l}\text { median age } 72 \text {; } \\
\text { female } n=9 \\
[45 \%])\end{array}$ & & not specified \\
\hline Grant et al., & USA & Home-based & CG (randomized & CG Enhanced & CG Sham & Pre-post & CSQ, CES-D \\
\hline $2002^{33}$ & & & $n=74)$ & $\begin{array}{l}\text { psychosocial } \\
\text { support }\end{array}$ & $\begin{array}{l}\text { intervention OR } \\
\text { UC }\end{array}$ & & \\
\hline
\end{tabular}




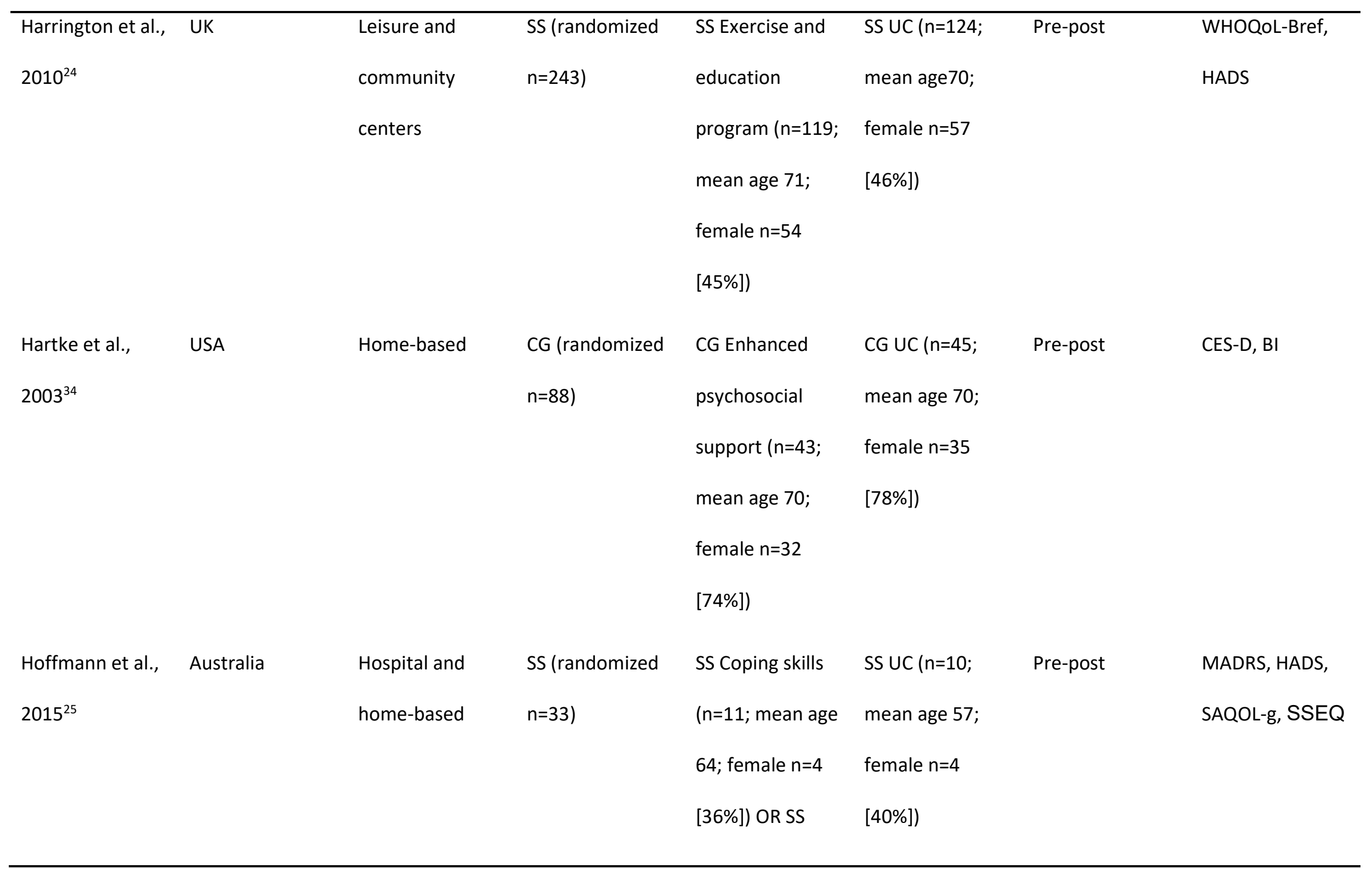




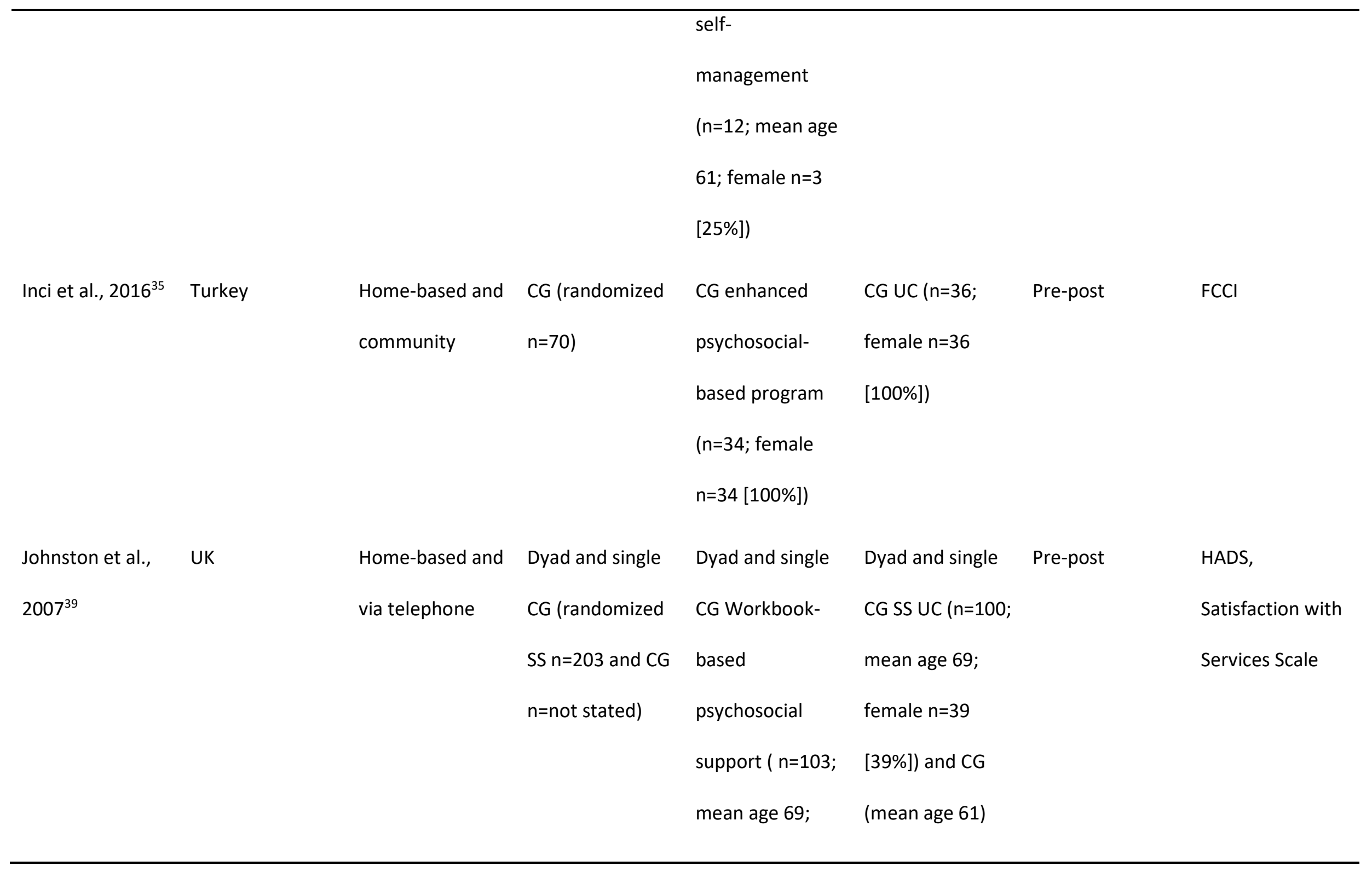




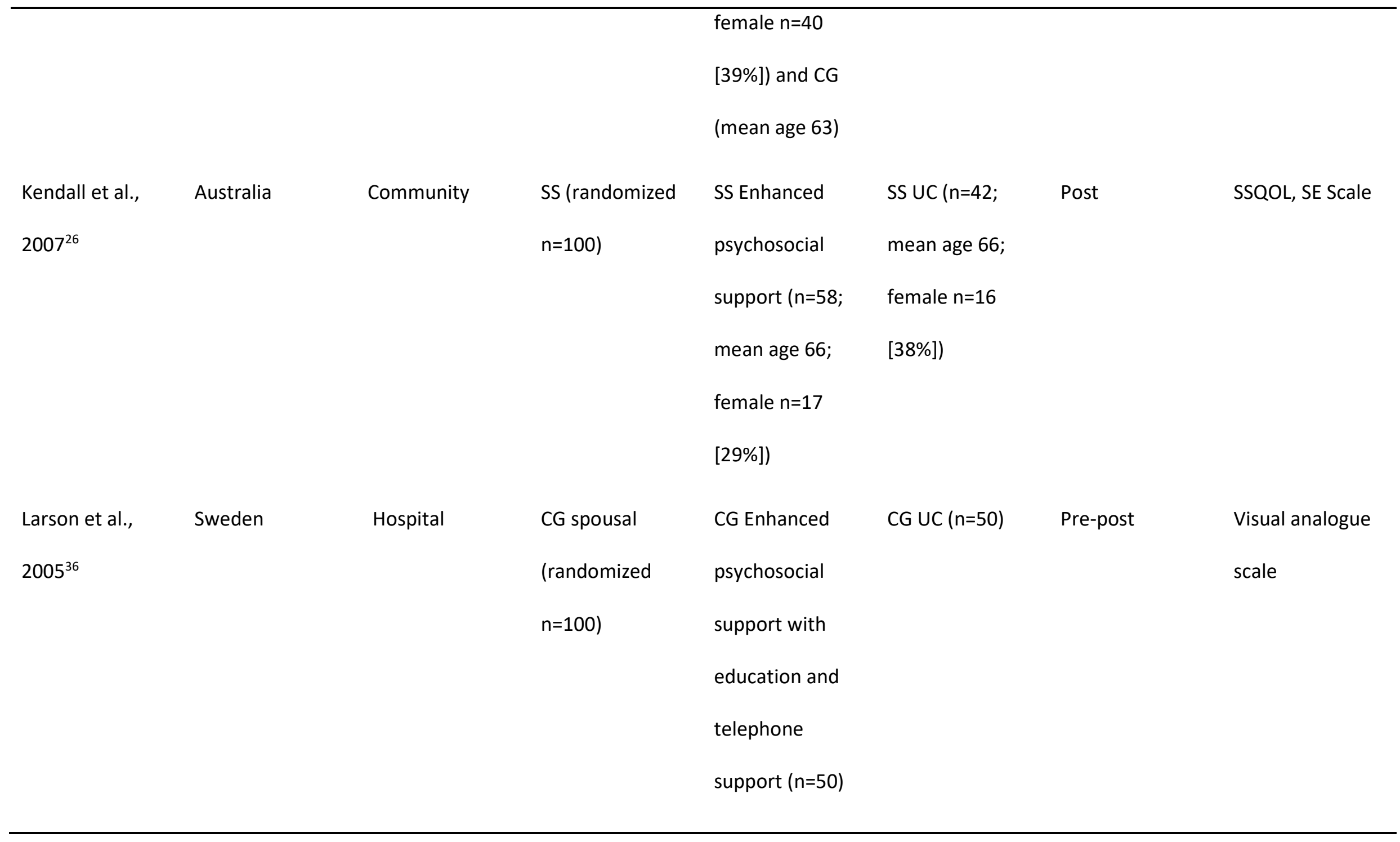




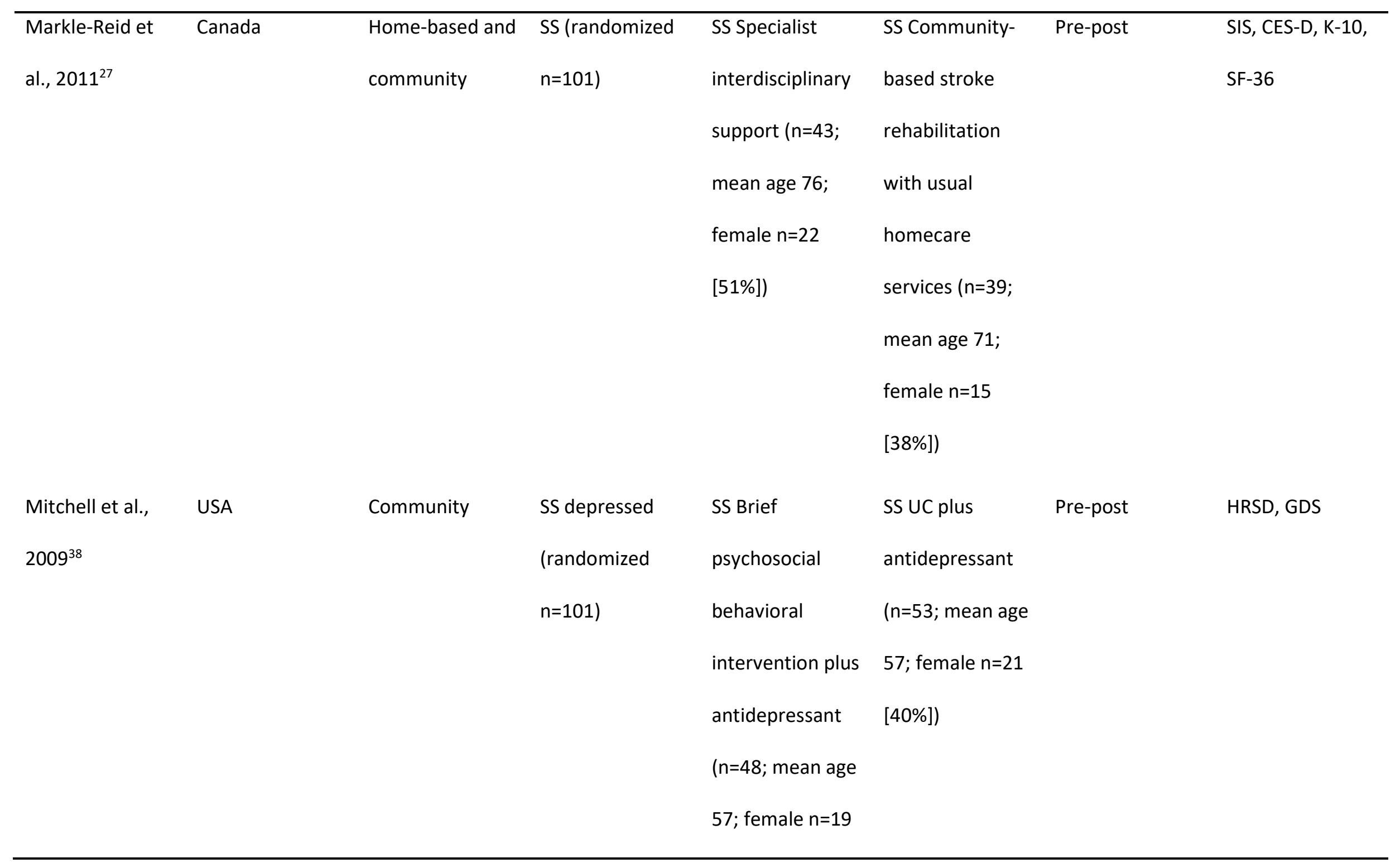




\begin{tabular}{|c|c|c|c|c|c|c|c|}
\hline \multirow[b]{2}{*}{ Ostwald et al., } & \multirow[b]{2}{*}{ USA } & \multirow[b]{2}{*}{ Home-based } & \multirow[b]{2}{*}{ Dyad } & \multicolumn{2}{|l|}{ [40\%]) } & \multirow[b]{2}{*}{ Pre-post } & \multirow[b]{2}{*}{ F-COPES, GDS } \\
\hline & & & & Dyad Brief & Dyad & & \\
\hline \multirow[t]{9}{*}{$2014^{46}$} & & & (randomized & psychosocial & Information plus & & \\
\hline & & & $\mathrm{n}=159$ dyads) & behavioral and & UC SS (n=79; & & \\
\hline & & & & information SS & mean age 66; & & \\
\hline & & & & ( $n=80 ;$ mean age & female $n=15$ & & \\
\hline & & & & 67 ; female $n=25$ & [19\%]) and CG & & \\
\hline & & & & $[31 \%])$ and CG & ( $n=79 ;$ mean age & & \\
\hline & & & & ( $n=80 ;$ mean age & $61 ;$ Female $n=64$ & & \\
\hline & & & & $64 ;$ female $n=55$ & [81\%]) & & \\
\hline & & & & [69\%]) & & & \\
\hline \multirow[t]{5}{*}{ Robinson-Smith } & USA & Home-based & Dyads & Dyad Enhanced & Dyad UCSS & Pre-post & DCl, QLI-stroke, \\
\hline & & & (randomized & psychosocial & $(n=5 ;$ mean age & & SUPPH, CES-D \\
\hline & & & $\mathrm{n}=10$ dyads) & program. SS & 77; female $n=2$ & & \\
\hline & & & & ( $n=5 ;$ mean age & [40\%]) and CG & & \\
\hline & & & & $65 ;$ female $n=2$ & ( $n=5 ;$ mean age & & \\
\hline
\end{tabular}




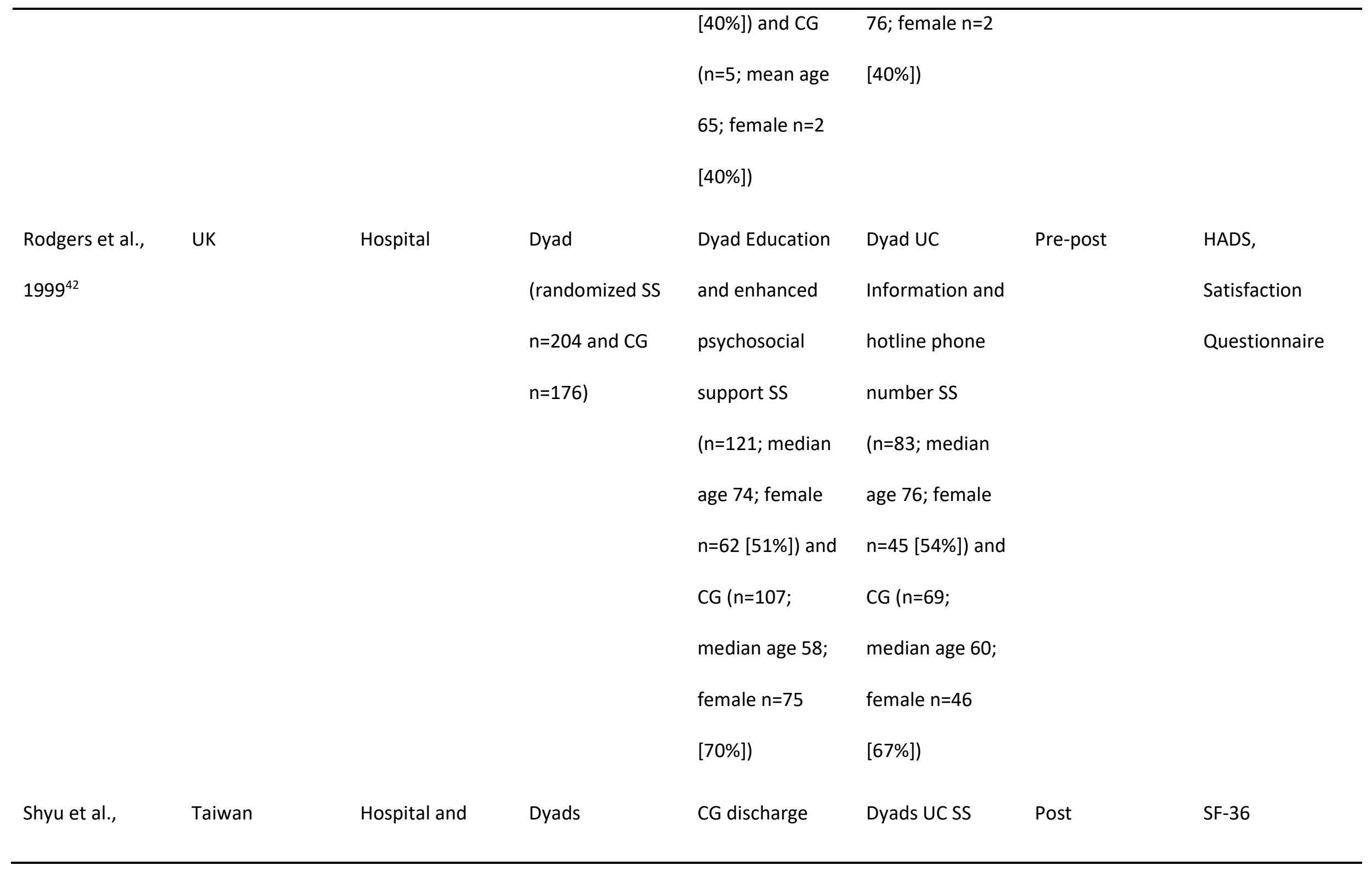




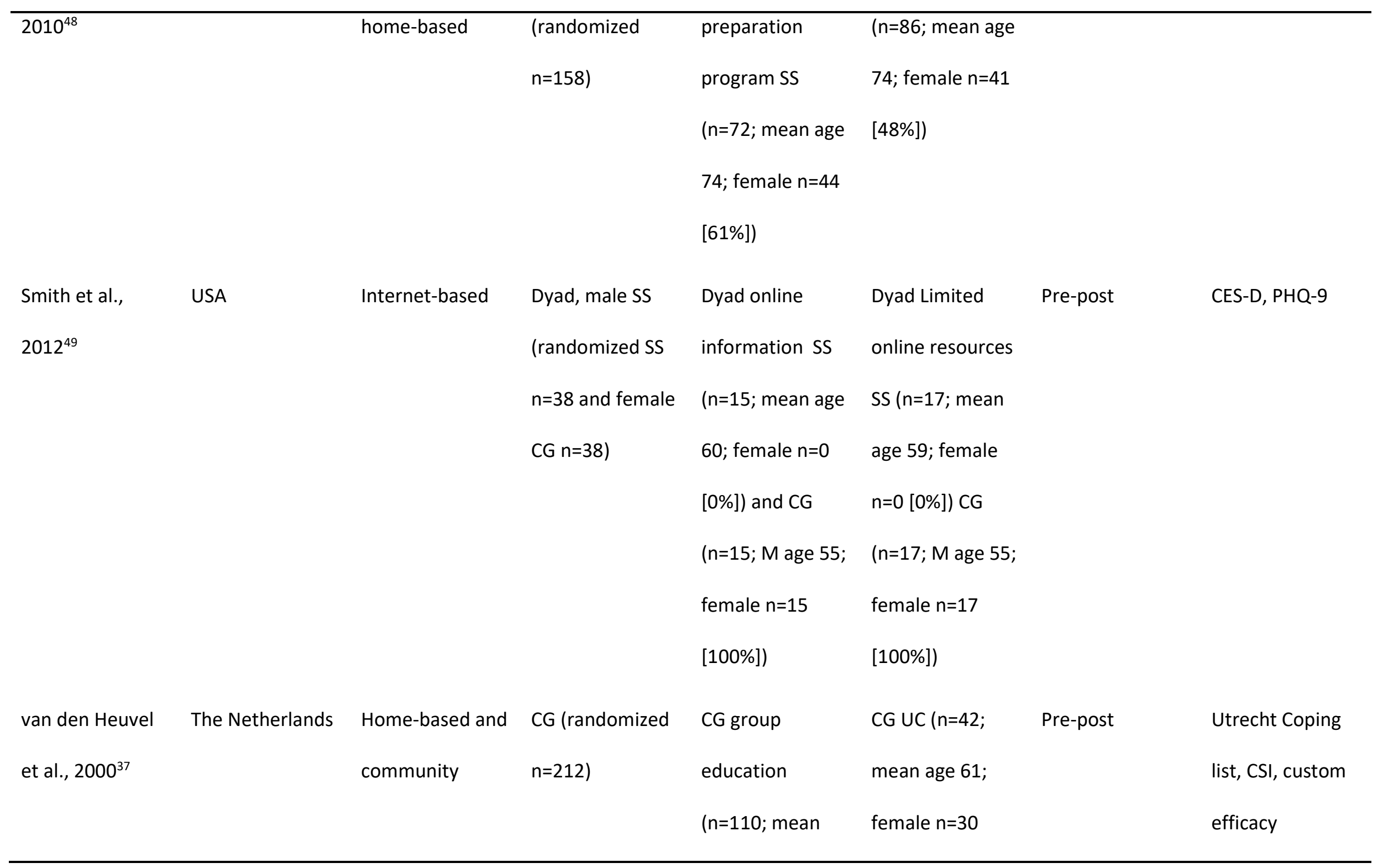




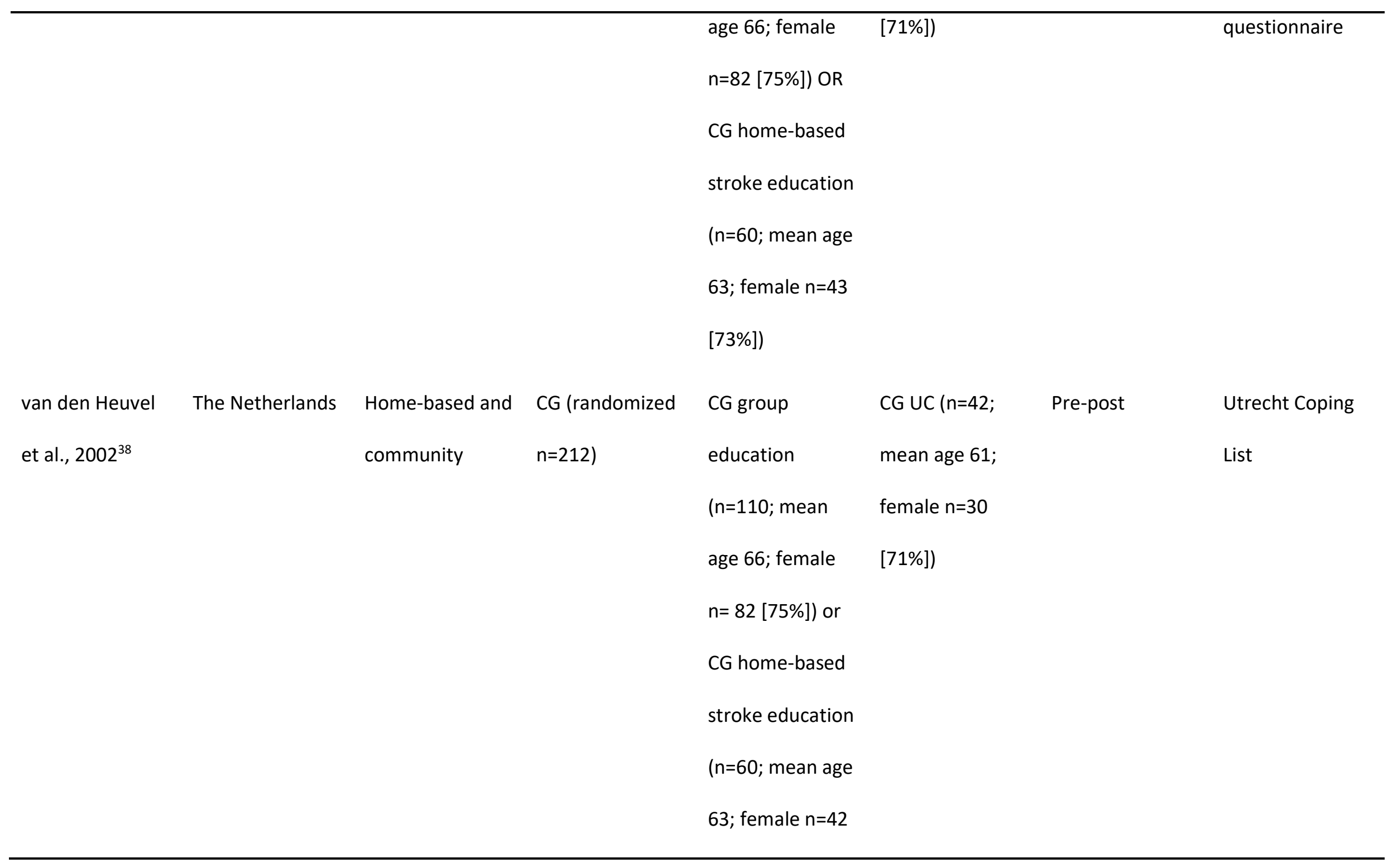




\begin{tabular}{|c|c|c|c|c|c|c|c|}
\hline & & & & $[71 \%])$ & & & \\
\hline Watkins et al., & UK & Hospital and & SS (randomized & SS Motivational & SS UC $n=207$ & Pre-post & Yale Depression \\
\hline \multirow[t]{4}{*}{$2007^{29}$} & & home-based & $\mathrm{n}=411)$ & interviewing & median age 70 ; & & Screen \\
\hline & & & & ( $n=204 ;$ median & female $n=85$ & & \\
\hline & & & & age 70 ; female & [41\%]) & & \\
\hline & & & & $\mathrm{n}=86[40 \%])$ & & & \\
\hline Wong et al., & Hong Kong & Hospital and & SS (randomized & SS Transitional & SS UC $(n=54 ;$ & Pre-post & CES-D-HK, WHO- \\
\hline \multirow[t]{4}{*}{$2015^{30}$} & & home-based & $n=108)$ & care program & mean age $72 ;$ & & QOL- SRPB \\
\hline & & & & ( $n=54 ;$ mean age & female $n=34$ & & \\
\hline & & & & 66 ; female $n=34$ & [63\%]) & & \\
\hline & & & & [63\%]) & & & \\
\hline
\end{tabular}




\section{Figures}

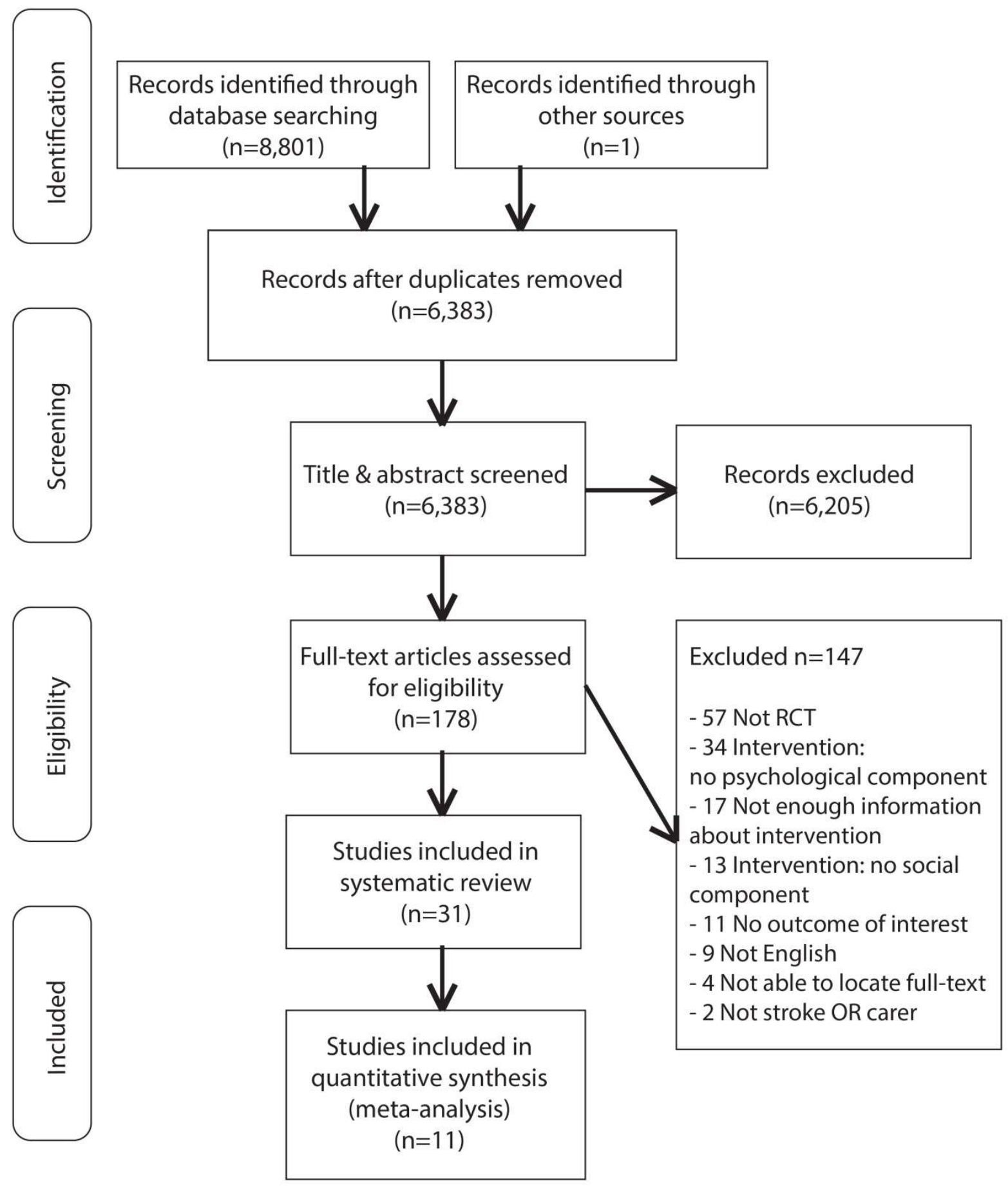

Figure 1. PRISMA flow diagram of included studies 


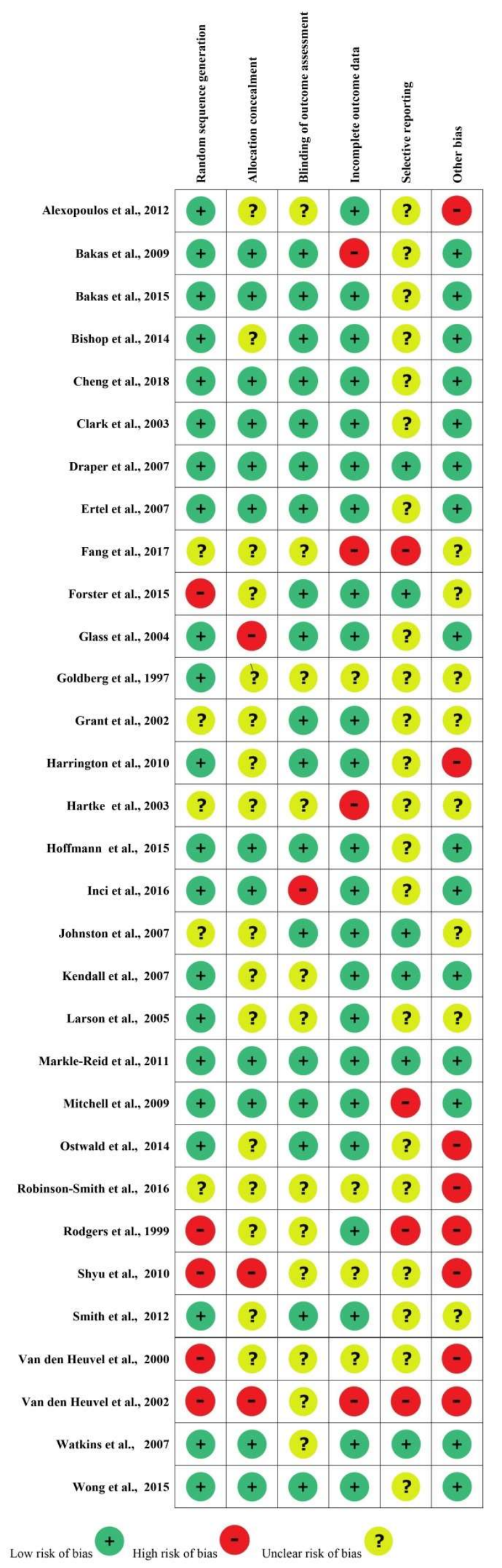

Figure 2. Risk of bias 


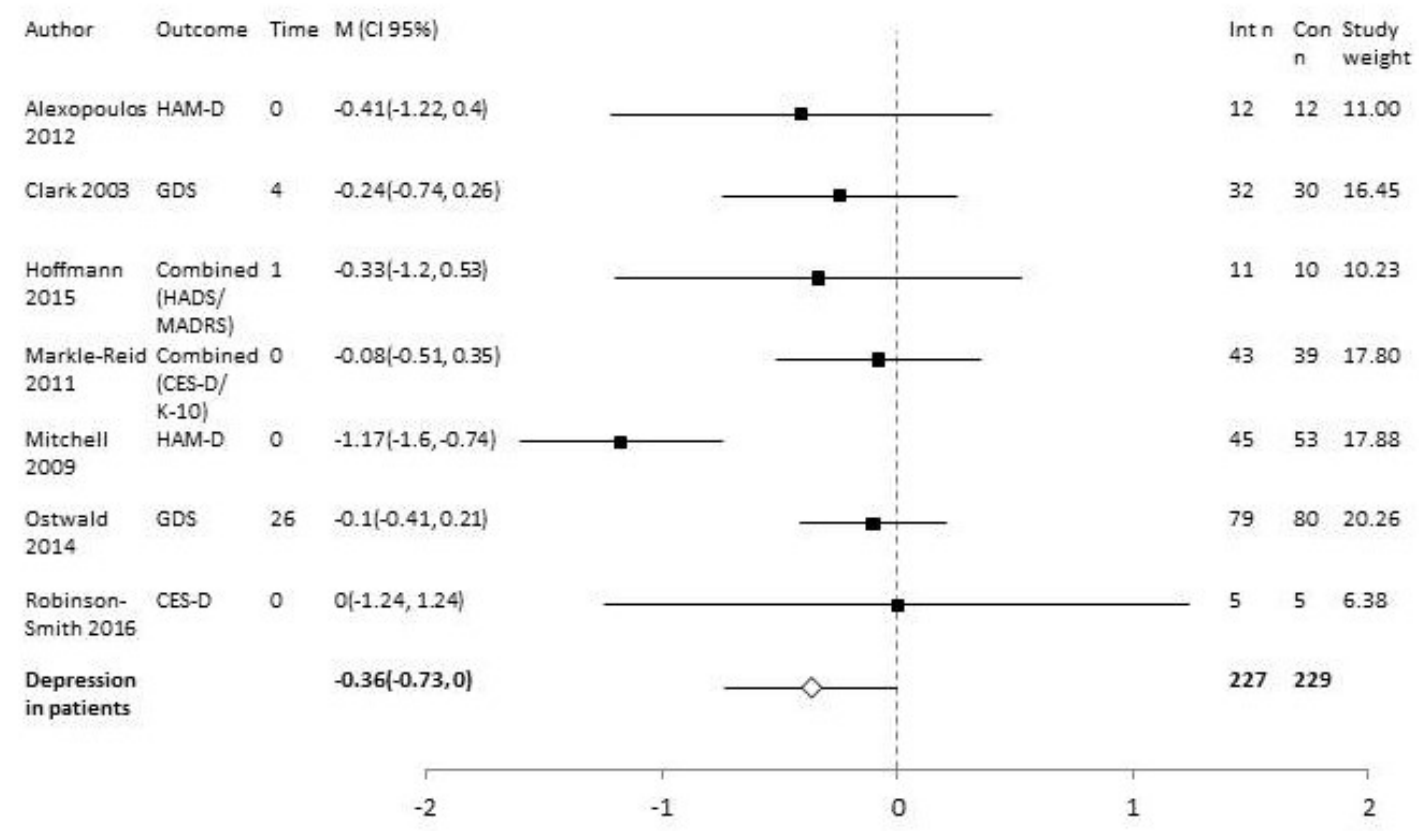

Figure 3. Forest plot - Interventions delivered to stroke survivors or dyads and depressive symptoms measured in stroke survivors 


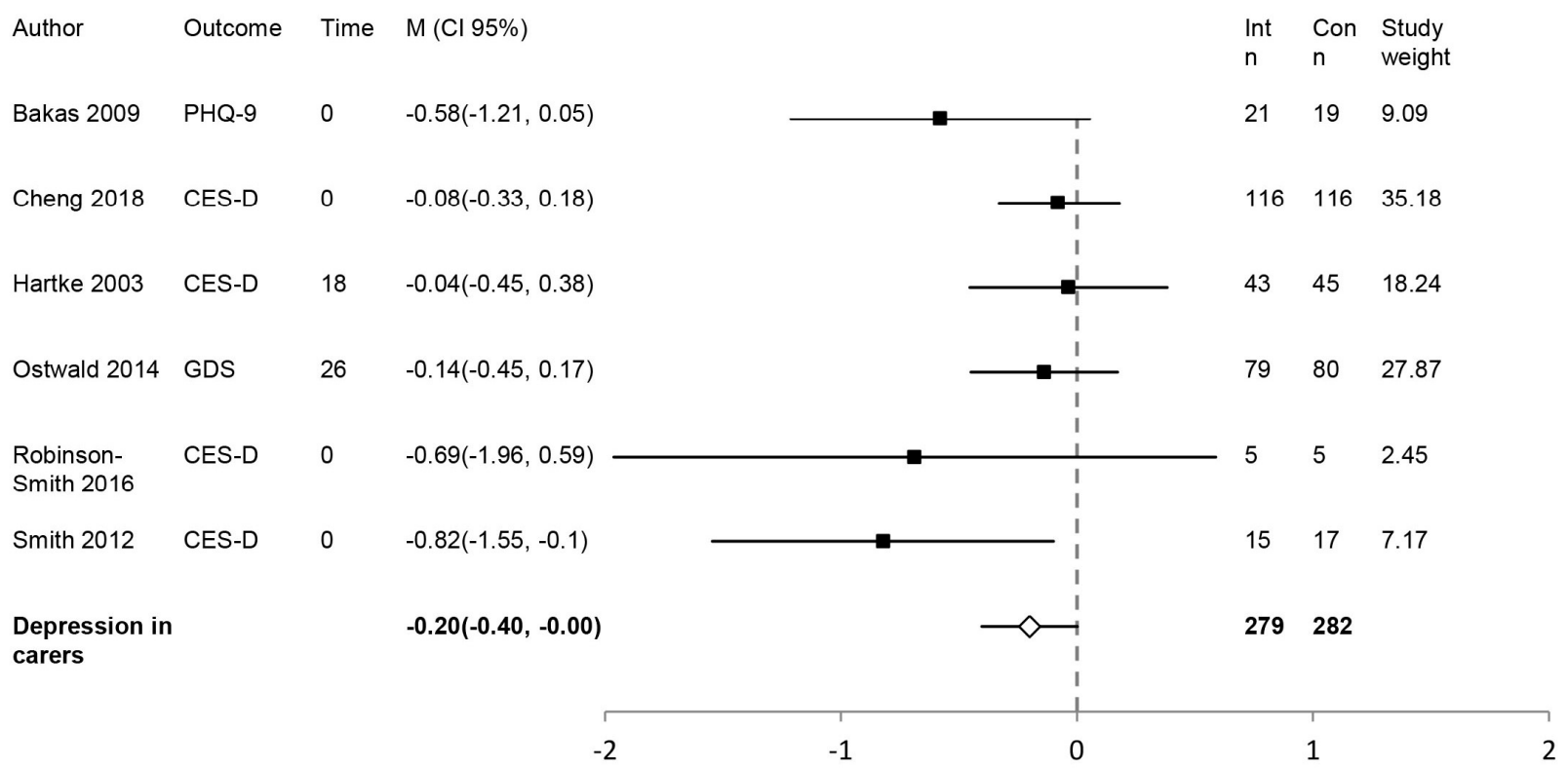

Figure 4. Forest plot - Interventions delivered to carers or dyads and depressive symptoms measured in carers 


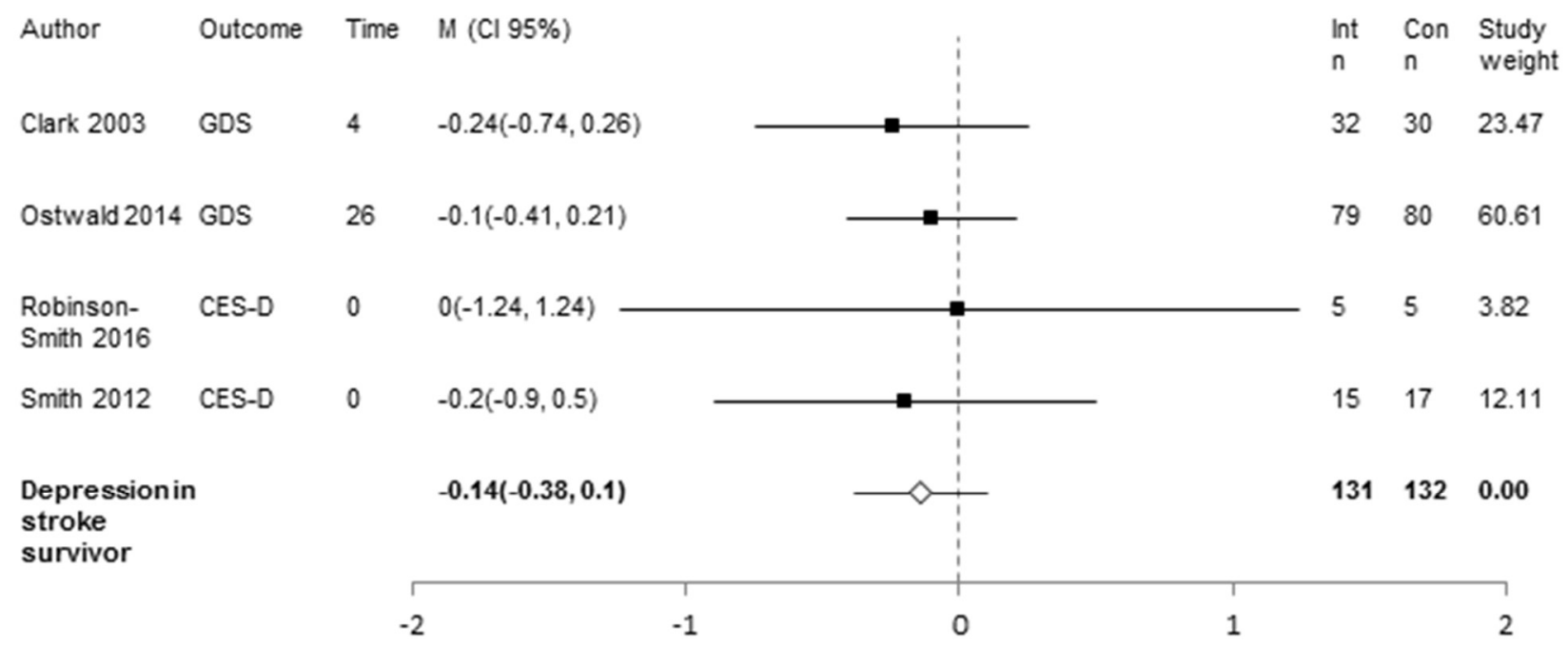

Figure 5. Forest plot - Interventions delivered to carers or dyads and depressive symptoms measured in stroke survivors 
Supplementary Figure. Meta-analysis funnel plots

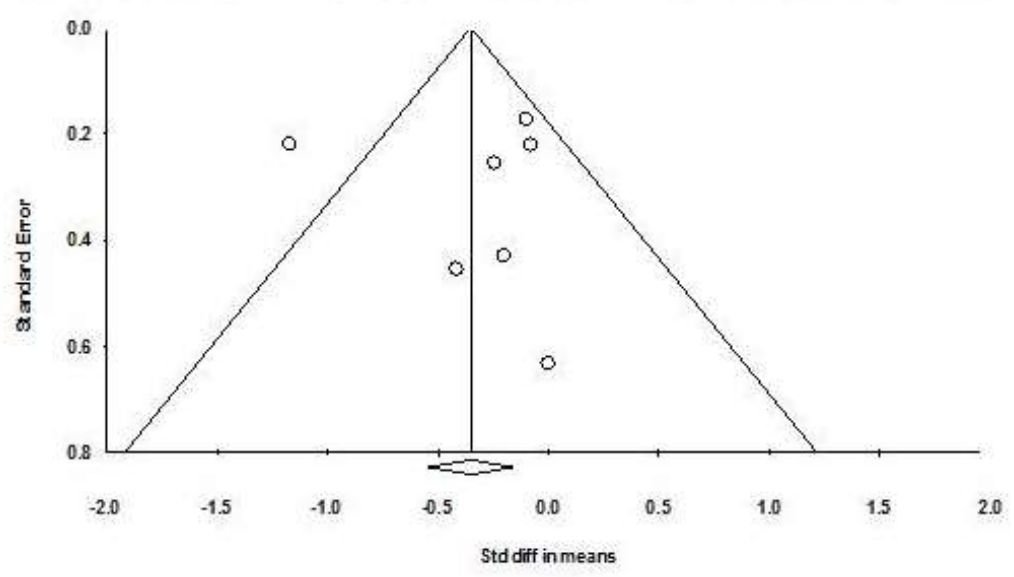

Supplementary Figure A. Funnel plot - Interventions delivered to stroke survivors or dyads and depressive symptoms measured in stroke survivors 


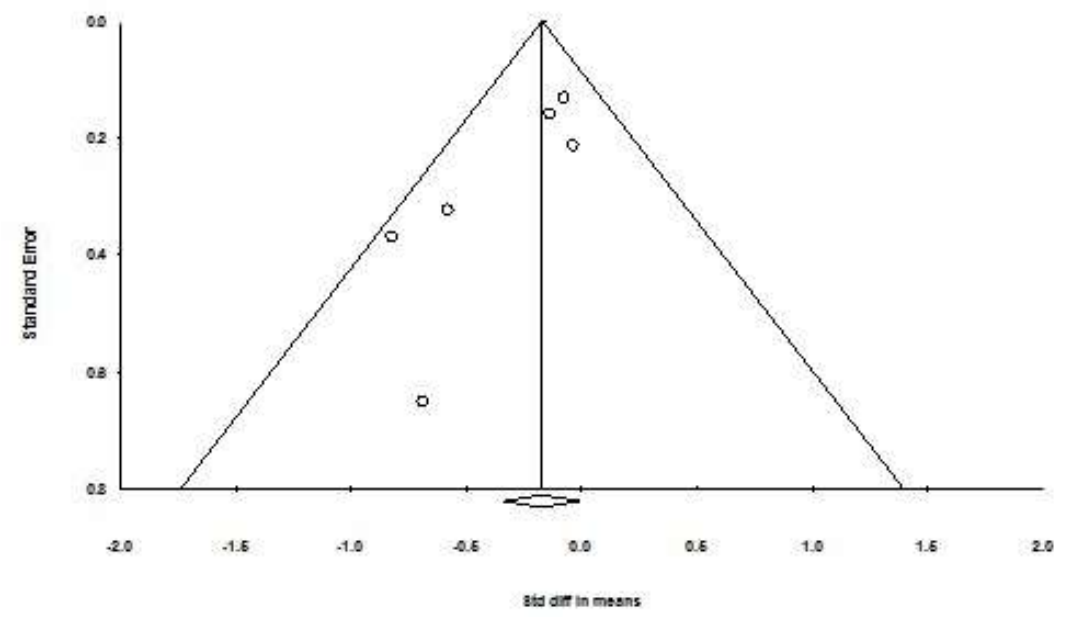

Supplementary Figure B. Funnel plot - Interventions delivered to carers or dyads and depressive symptoms measured in carers 


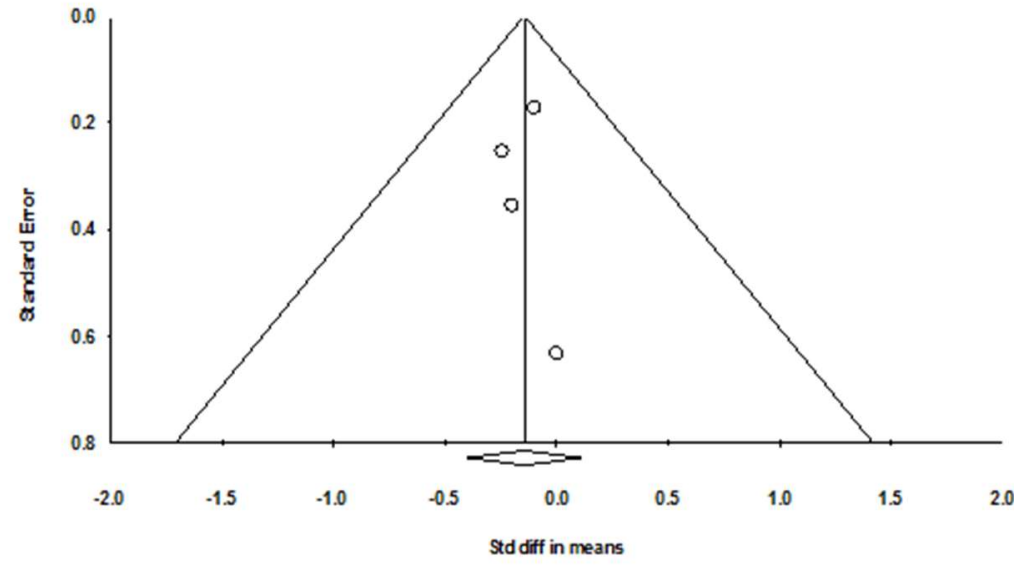

Supplementary Figure C. Forest plot - Interventions delivered to carers or dyads and depressive symptoms measured in stroke survivors 